NASA/TM-2005-213667

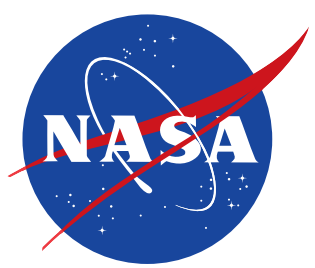

\title{
Shock Location Dominated Transonic Flight Loads on the Active Aeroelastic Wing
}

William A. Lokos and Andrew Lizotte

NASA Dryden Flight Research Center

Edwards, California

Ned J. Lindsley

AFRL/VASD

Wright Patterson, Ohio

Rick Stauf

Spiral Technology, Inc.

Edwards, California 


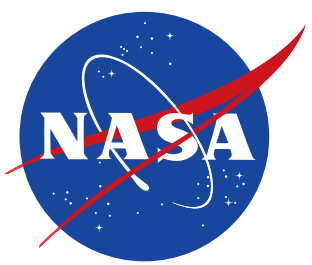

\section{Shock Location Dominated Transonic Flight Loads on the Active Aeroelastic Wing}

William A. Lokos and Andrew Lizotte

NASA Dryden Flight Research Center

Edwards, California

Ned J. Lindsley

AFRL/VASD

Wright Patterson, Ohio

Rick Stauf

Spiral Technology, Inc.

Edwards, California

National Aeronautics and

Space Administration

Dryden Flight Research Center

Edwards, California 93523-0273 


\begin{abstract}
During several Active Aeroelastic Wing research flights, the shadow of the over-wing shock could be observed because of natural lighting conditions. As the plane accelerated, the shock location moved aft, and as the shadow passed the aileron and trailing-edge flap hinge lines, their associated hinge moments were substantially affected. The observation of the dominant effect of shock location on aft control surface hinge moments led to this investigation. This report investigates the effect of over-wing shock location on wing loads through flight-measured data and analytical predictions. Wing-root and wing-fold bending moment and torque and leading- and trailing-edge hinge moments have been measured in flight using calibrated strain gages. These same loads have been predicted using a computational fluid dynamics code called the Euler Navier-Stokes Three Dimensional Aeroelastic Code. The computational fluid dynamics study was based on the elastically deformed shape estimated by a twist model, which in turn was derived from in-flight-measured wing deflections provided by a flight deflection measurement system. During level transonic flight, the shock location dominated the wing trailing-edge control surface hinge moments. The computational fluid dynamics analysis based on the shape provided by the flight deflection measurement system produced very similar results and substantially correlated with the measured loads data.
\end{abstract}

\title{
NOMENCLATURE
}

\begin{tabular}{ll} 
AAW & Active Aeroelastic Wing \\
AIL & aileron \\
$C_{D}$ & coefficient of drag \\
$C_{L}$ & coefficient of lift \\
$C_{m}$ & coefficient of moment \\
CFD & computational fluid dynamics \\
\hline CS & loads calculated using computational fluid dynamics \\
deg & control surface \\
ENS3DAE & Euler Navier-Stokes Three Dimensional Aeroelastic Code \\
$F_{x}$ & longitudinal force, lb \\
$F_{y}$ & lateral force, lb \\
$F_{z}$ & normal force, lb \\
FDMS & flight deflection measurement system \\
\hline & loads measured during flight \\
\hline ILEF & control surface inboard position measured during flight, deg \\
LAIL & inboard leading-edge flap \\
LAIL CR1 & left aileron \\
& left aileron criticality ratio (percent of load limit), prime
\end{tabular}


LILEF left inboard leading-edge flap

LITEF CR1 left inboard trailing-edge flap criticality ratio (percent of load limit), prime

LOLEF left outboard leading-edge flap

LSTAB left stabilator (horizontal, "rolling" tail)

LTEF left trailing-edge flap

$\angle W F B N D \quad$ left wing-fold bending moment, in.-lb

LWFTRQ left wing-fold torque, in.-lb

LWING left wing

LWRBND left wing-root bending moment, in.-lb

LWRTRQ left wing-root torque, in.-lb

$M \quad$ Mach number

$M_{\infty} \quad$ free-stream Mach number

$-o b \quad$ control surface outboard position measured during flight, deg

OLEF outboard leading-edge flap

RAIL CR1 right aileron criticality ratio, prime

RITEF CR1 right inboard trailing-edge flap criticality ratio (percent of load limit), prime

TEF trailing-edge flap

$X_{c} \quad$ longitudinal centroid location, in.

$Y_{c} \quad$ lateral centroid location, in.

$Z_{c} \quad$ vertical centroid location, in.

$\alpha \quad$ angle of attack, deg

\section{INTRODUCTION}

For over a decade it has been proposed that wing torsional flexibility could be used to aeroelastically enhance the roll maneuverability of a high performance aircraft. Although aeroelastic control behavior related to aileron reversal has, as a rule, always been avoided even at the expense of additional structural weight, it offers significant benefits when incorporated as a preprogrammed control mode. It has been proposed that if the aeroelastic control paradigm was designed into a new airframe, then lighter weight, increased maneuverability, and other advantages could be exploited (refs. 1-3).

The early version of the F/A-18 aircraft had the potential for aileron reversal within its performance envelope. Production F/A-18 aircraft were built with stiffer wings to preclude this tendency and increase roll performance through conventional wing control surface use (refs. 4, 5). The NASA Active Aeroelastic Wing (AAW) F/A-18 aircraft (fig. 1) has been structurally modified to support aeroelastic flight control research. The aft wing box skins were replaced with more flexible panels to essentially replicate the stiffness of the original preproduction F/A-18 aircraft. The aircraft was extensively 
instrumented for this research effort, including the installation of numerous strain gage bridges, accelerometers, and control surface position transducers on the wings. A wing deflection measurement system was installed on the left wing to track elastic structural displacements. An over-the-wing video camera provided real-time imagery of the upper surface of the left wing. Flight loads measured by the strain gages were monitored in real time for flight safety.

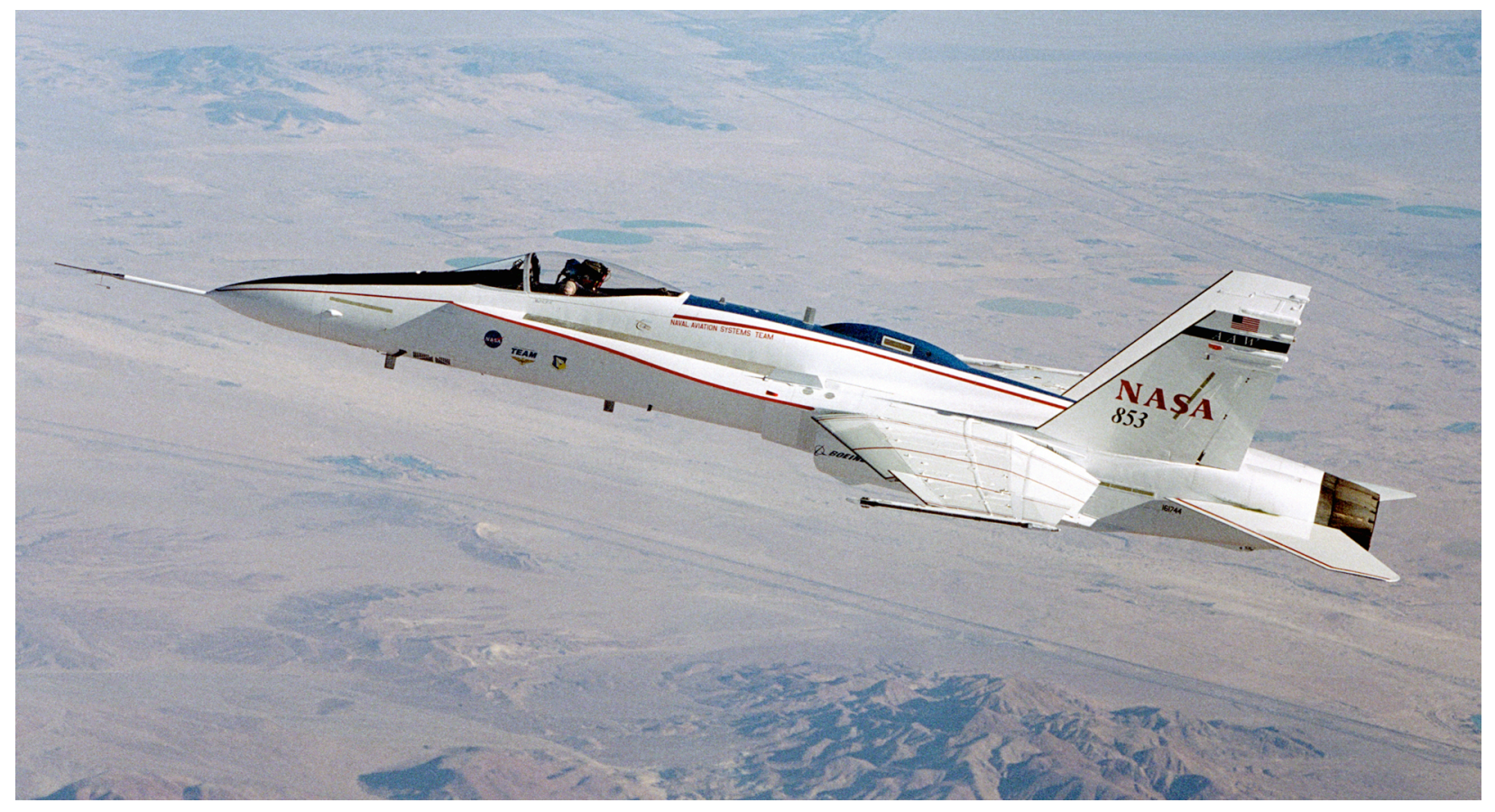

EC02-0264-19

Figure 1. Active Aeroelastic Wing aircraft in flight.

When transonic conditions were experienced during the first flight block of the AAW (ref. 6), natural lighting conditions occasionally were such that the over-wing shock on the left wing was visible on the real-time flight video image. As the Mach number changed, this shock wave translated across the wing. These natural shadowgraphs have been noticed by flyers since the 1940s (ref. 7). Two successive times during an observable shock wave occurrence, as the shock wave translated past a certain point on the wing, the trailing-edge hinge moments abruptly offset from their previous levels.

This report investigates these shock location dominated transonic flight loads. The measurement of AAW flight loads, prediction of flight loads and shock locations, and natural flow visualization of the over-wing shock wave are discussed. Predicted and measured shock-induced loads are compared and contrasted.

\section{MEASUREMENTS AND OBSERVATIONS}

The AAW project was designed with substantial load measurement features so that the full strength envelope of the test aircraft could be exploited. As significant aeroelastic behavior was targeted, real-time wing deflection measurement was planned. Many other research measurements were included. 
Flight load measurement was accomplished through the use of 200 four-active-arm strain gage bridges installed on the test wings. These strain gages were calibrated through an extensive ground loads calibration test (ref. 8). Twenty component load measurements (fig. 2) were measured on the AAW from the installed strain gages and the application of the corresponding load equations. During the AAW flight tests, the loads measured by the strain gages were monitored in real time and recorded on the ground. Wing deflection measurement was provided through the installation of an electro-optical flight deflection measurement system (FDMS) (refs. 9-12) on the left wing. Aircraft state parameters and various video signals also were monitored and recorded for the purpose of research and general situational awareness. The upper surface of the left wing was imaged by one of the onboard video cameras. This video was useful for research augmentation to the FDMS (ref. 13) and for occasional viewing of over-wing shock wave indications.

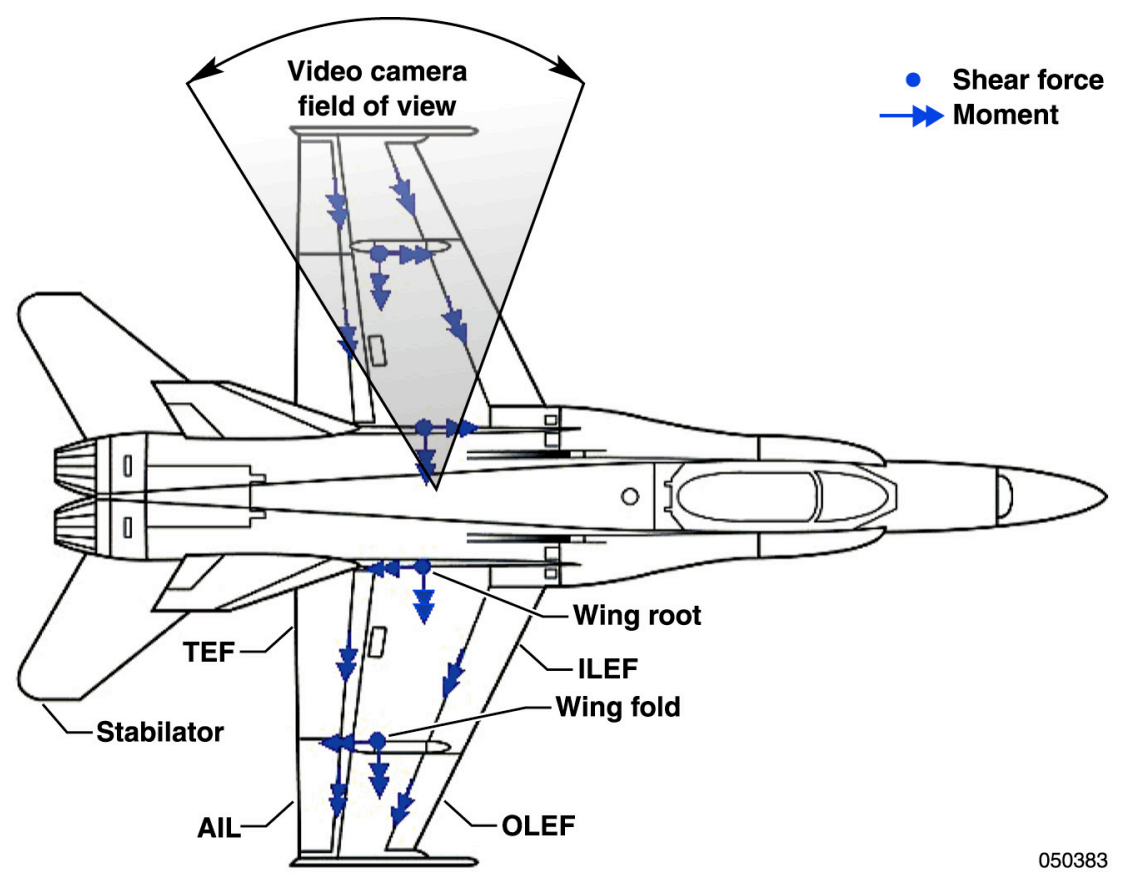

Figure 2. Active Aeroelastic Wing measured loads.

Figure 3 shows a time history of the left and right aileron and trailing-edge flap hinge moments for the time interval during a transonic level acceleration. The left and right aileron data closely agree as do the left and right trailing-edge flap data sets. Of interest is the significant change in aileron hinge moment starting at 0.5 seconds into the time record closely followed by a similar change in the trailing-edge flap hinge moment. The cause of these hinge moment offsets, discovered through the use of real-time video data, was the progressive translation of the over-wing shock wave first across the aileron hinge line and then across the trailing-edge flap hinge line. Figure 4 presents a composite photo produced from three still frames clipped from the wing video signal. This video based information corresponds to the measured load data shown in figure 3. The three shock wave shadows were circled at Mach 0.94 (orange), 0.95 (magenta), and 0.96 (blue) for clarity, because the shadows are more difficult to see in a still photo than in the moving video image. As Mach number increased, the shock location, as indicated 
by the visible shadow, translated aft. The aileron hinge moment drop occurred at Mach 0.95, and the trailing-edge flap hinge moment was similarly affected at Mach 0.96.

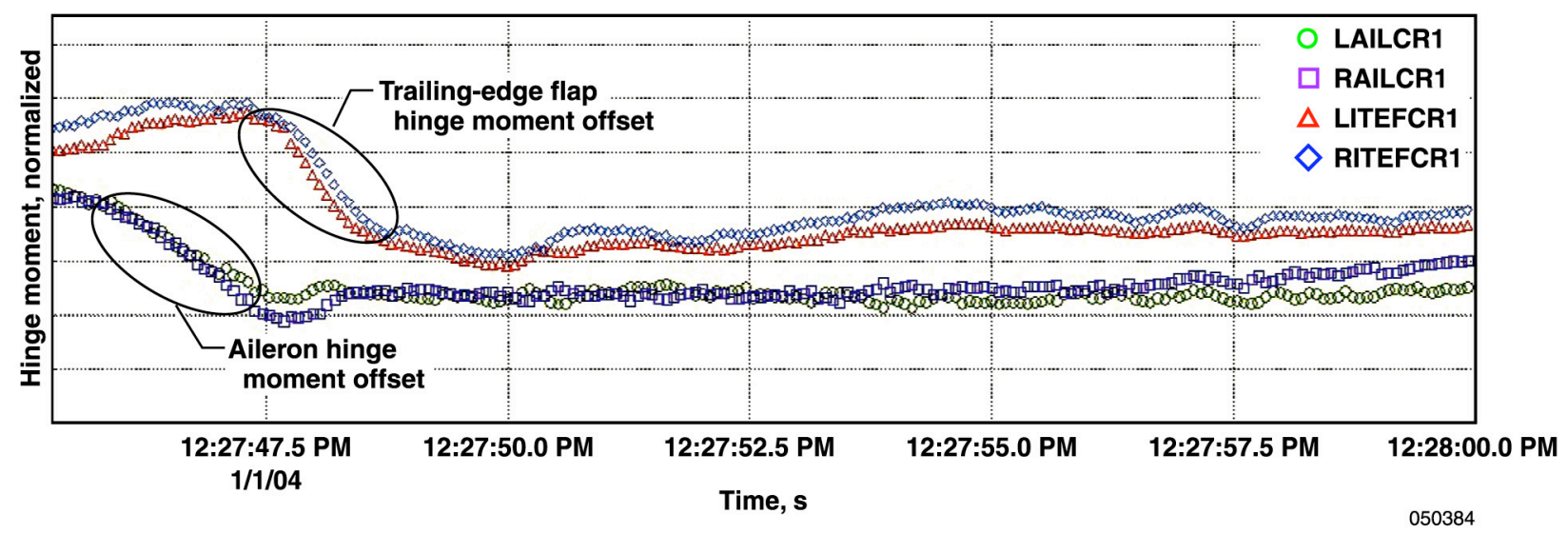

Figure 3. Measured aileron and trailing-edge flap hinge moments during shock translation.

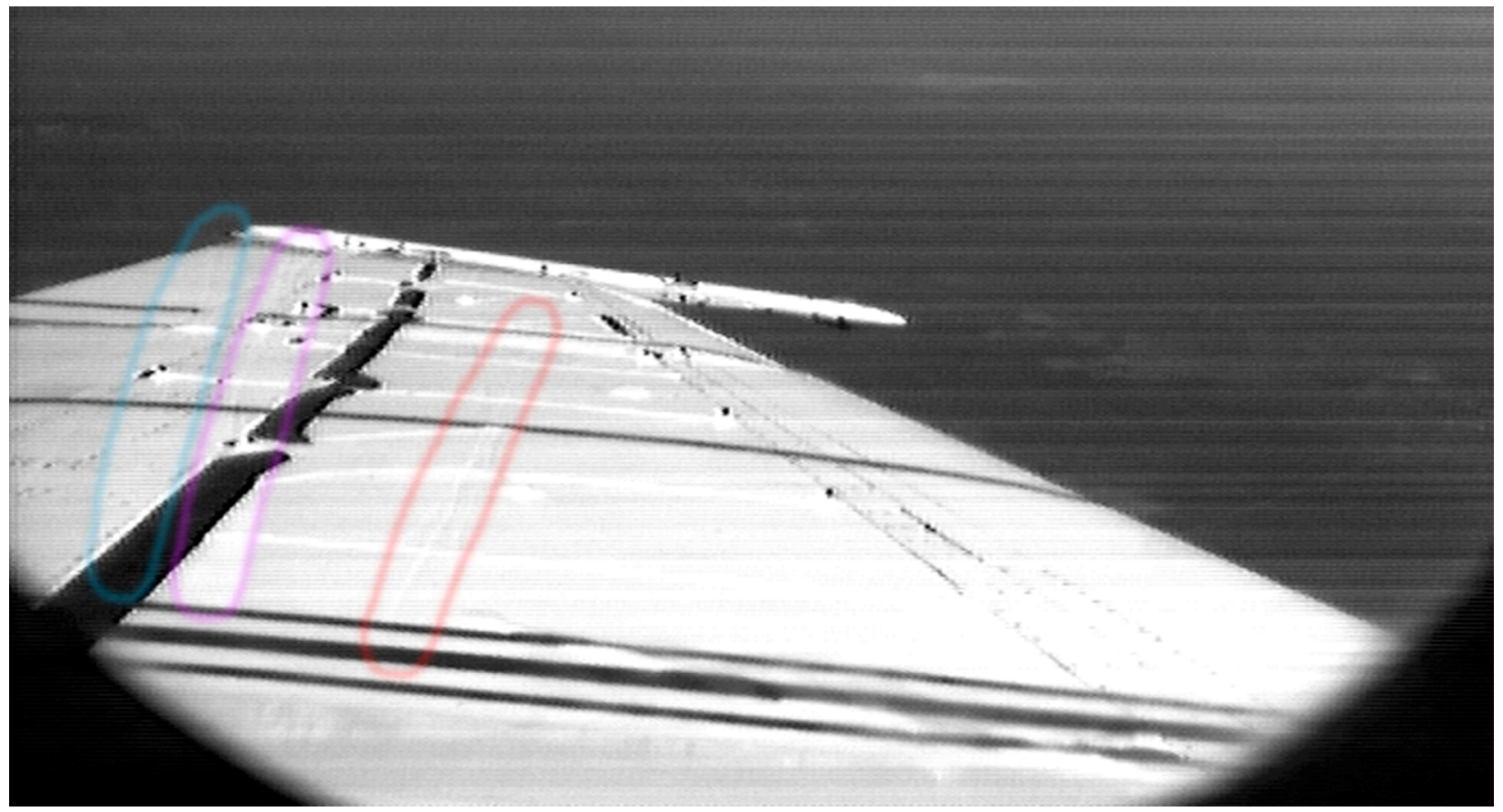

ED03-0198-01

Figure 4. Composite of three over-wing video frames showing shock wave shadow locations at three Mach numbers.

The observation of the relationship between over-wing shock wave location and measured control surface hinge moments prompted further study by means of current computational fluid dynamics (CFD) 
tools. Wing elastic shape information measured in flight enabled the study of the aircraft aerodynamics resulting from the deformed condition.

\section{COMPUTATIONAL METHODOLOGY}

A CFD code called the Euler Navier-Stokes Three Dimensional Aeroelastic Code (ENS3DAE) (ref. 14) was employed to calculate wing upper and lower surface pressures. The aerodynamic analysis procedure employed by ENS3DAE uses an implicit finite difference algorithm to integrate either the Euler or Navier-Stokes equations in general nonorthogonal curvilinear coordinates. The equations are solved using a spatially varying time step for steady-state computations.

Time and budget had to be balanced with physical accuracy considerations. Therefore, the choice was made to run the CFD in an inviscid mode on the wing only with reflective boundary conditions, and with no free edges between the control surfaces. This approach was considered adequate for capturing the shocks associated with transonic flow behavior; however, viscous effects, "scissor" effects between control surfaces, and fuselage-wing leading-edge extension boundary condition effects at the wing root were not modeled.

As shown in figure 5, wing pressure distribution predictions were developed using a combination of tools. The CFD code was coupled with data measured during flight, which included control surface deflections and wing elastic deformations from the FDMS. The wing elastic deformations measured by the FDMS were characterized and carried into the CFD grid through the use of a twist algorithm (ref. 15) as an intermediary process. The FDMS was considered a more accurate, time saving, and convenient method of representing the structure (than finite element modeling prediction) for coupled interaction with the CFD aerodynamics.

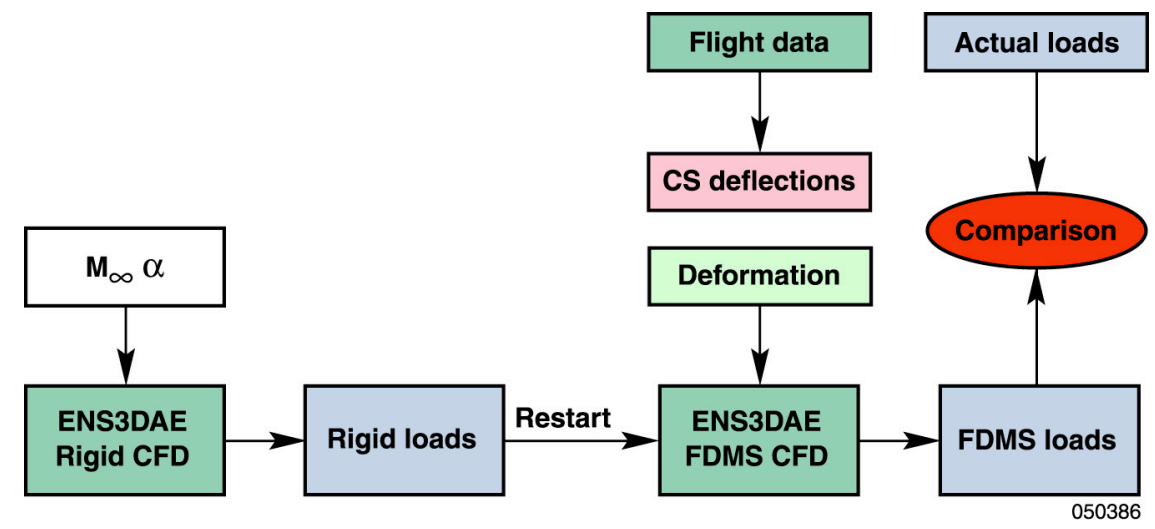

Figure 5. Flowchart of modeling, analysis, and experimental results comparison.

Referring again to figure 5, note that the CFD initially was run on the wing in its rigid or "jig shape" geometry (zero control surface deflections and elastic wing-box deformations), producing a set of loads for each Mach number ranging from 0.92 to 0.99 in increments of 0.01 . These solutions were used as restart conditions for the elastic, in-flight configuration of the wing, which produced a set of elastic loads for comparison with those measured in flight. In-house code was written to project the control surface 
and wing elastic deformations onto the CFD grid for the FDMS-CFD runs. The control surface deflections were input using the measured inboard and outboard deflection angles of each surface, with spanwise deflection varying linearly between the inboard and outboard edges. The angle of attack was constant with Mach number, reflecting the data measured in flight. The effect of stabilator (horizontal tail) position also was noted with regard to its influence on the upwash on the trailing-edge flap and the total aircraft lift.

Figure 6 shows the surface of the CFD grid used to model the AAW wing, with control surface boundaries demarcated. Figures 7 and 8 show the typical residual and force convergence histories, respectively, produced by the CFD analysis. The rigid CFD was run for 20,000 iterations, producing excellent convergence as evidenced by the time histories from iterations 15,000 to 20,000. The FDMS-CFD was run for 10,000 iterations, from 20,001 to 30,000. Figure 7 shows excellent residual convergence occurring from iteration 27,000 onward, and figure 8 shows a global force convergence (wing total $C_{L}, C_{D}, C_{m}$, and so forth) occurring somewhat sooner. Residual convergence was used as the governing convergence decision, thereby ensuring local force convergence. Local force convergence ensures converged solutions for the individual control surface, wing-root, and wing-fold loads. The results for the Mach 0.97 case are shown. This particular Mach number will be used to compare the rigid CFD to the FDMS-CFD for the typical case.

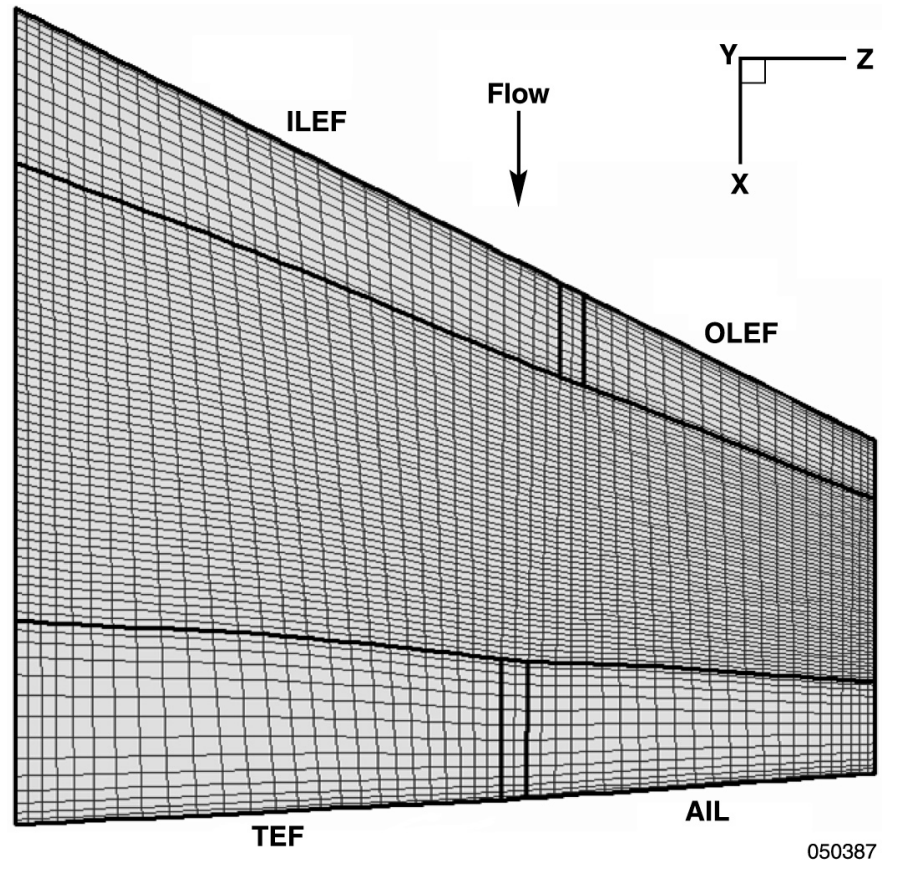

Figure 6. Surface of the computational fluid dynamics grid used to model the Active Aeroelastic Wing. 


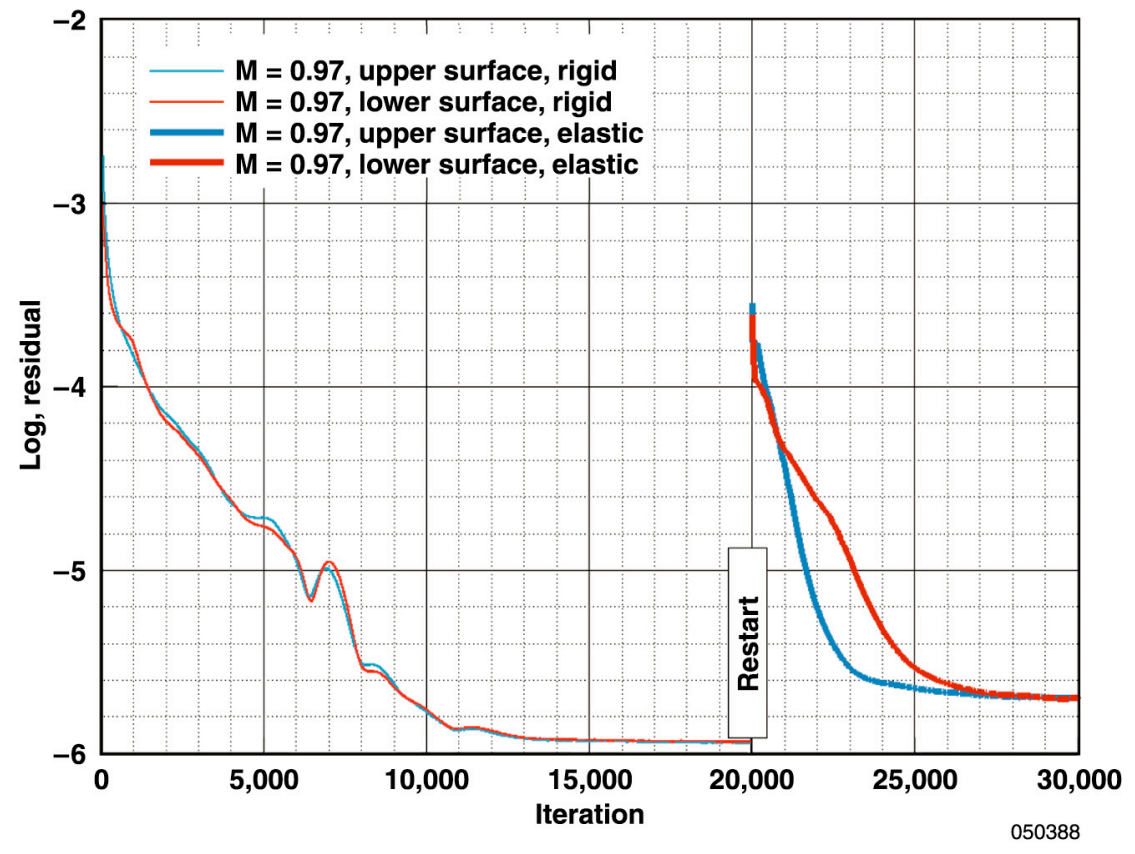

Figure 7. Typical residual convergence of the computational fluid dynamics model of the Active Aeroelastic Wing.

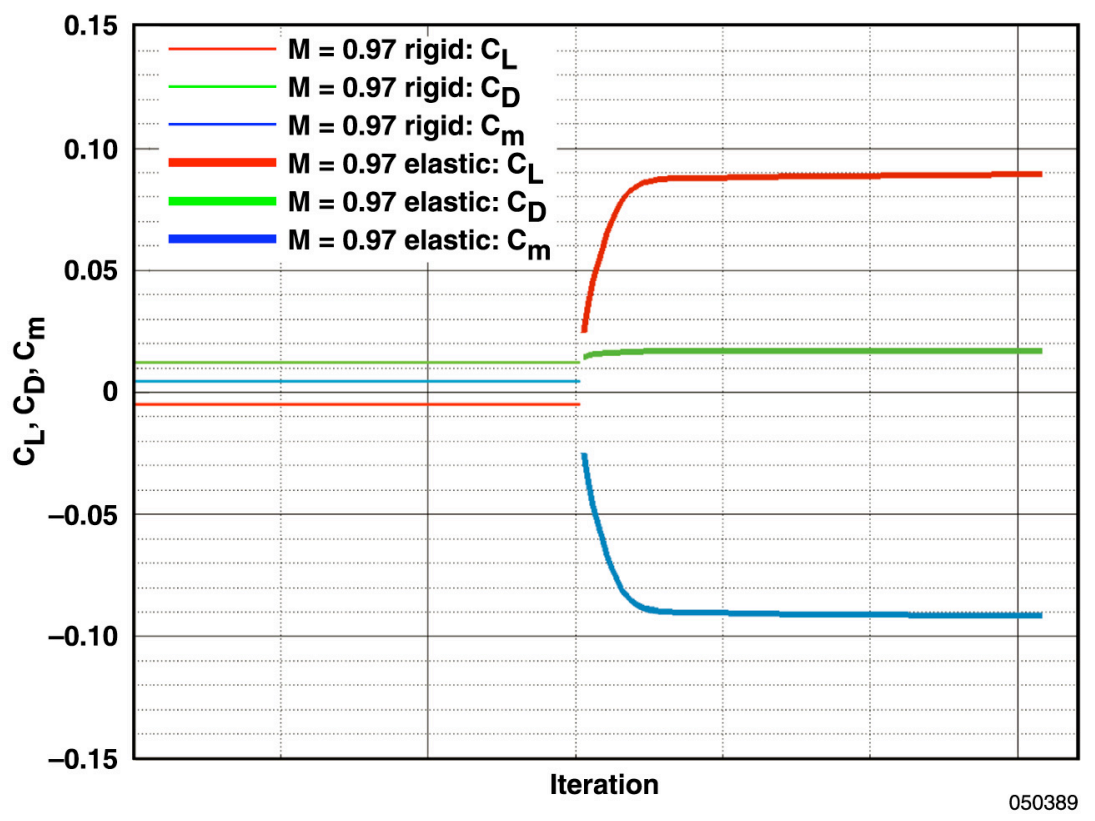

Figure 8. Typical force convergence of the computational fluid dynamics model of the Active Aeroelastic Wing. 


\section{RESULTS}

This research allows several comparisons to be made. The rigid CFD can be compared to the FDMS-based elastic CFD. The CFD results can be compared to flight-measured data. Further, the influence of modeling features may be noted.

\section{Comparison of Rigid CFD to FDMS-CFD}

Figures 9 and 10 show the resulting upper and lower wing surface pressure distributions (units psi), respectively, for a typical rigid CFD run. Figures 11 and 12 show the upper and lower wing surface pressures, respectively, for the FDMS-CFD. The contour scale is identical for all four figures, with a minimum (blue) to maximum (red) spectrum. A comparison between figures 9 and 11 shows that a much lower downward pressure occurred on the FDMS-CFD upper surface, particularly for the trailing-edge surfaces. Conversely, figures 10 and 12 show that a much higher upward pressure occurred on the FDMS-CFD lower surface, especially for the trailing-edge surfaces. These same trends, which account for the much higher lift (and loads) produced by the FDMS-CFD, also are evident to a somewhat lesser extent outboard of the wing fold. Figure 13, which shows the wing surface deflection contours measured by the FDMS (in inches), provides an explanation for these differences in surface pressure distributions. Imposing small leading-edge flap deflections and larger trailing-edge downward deflections, coupled with high bending and twist deflections outboard of the wing fold, naturally produce these changes in surface pressure because of the fluid-structure interaction typical of nonlinear aeroelastic systems.

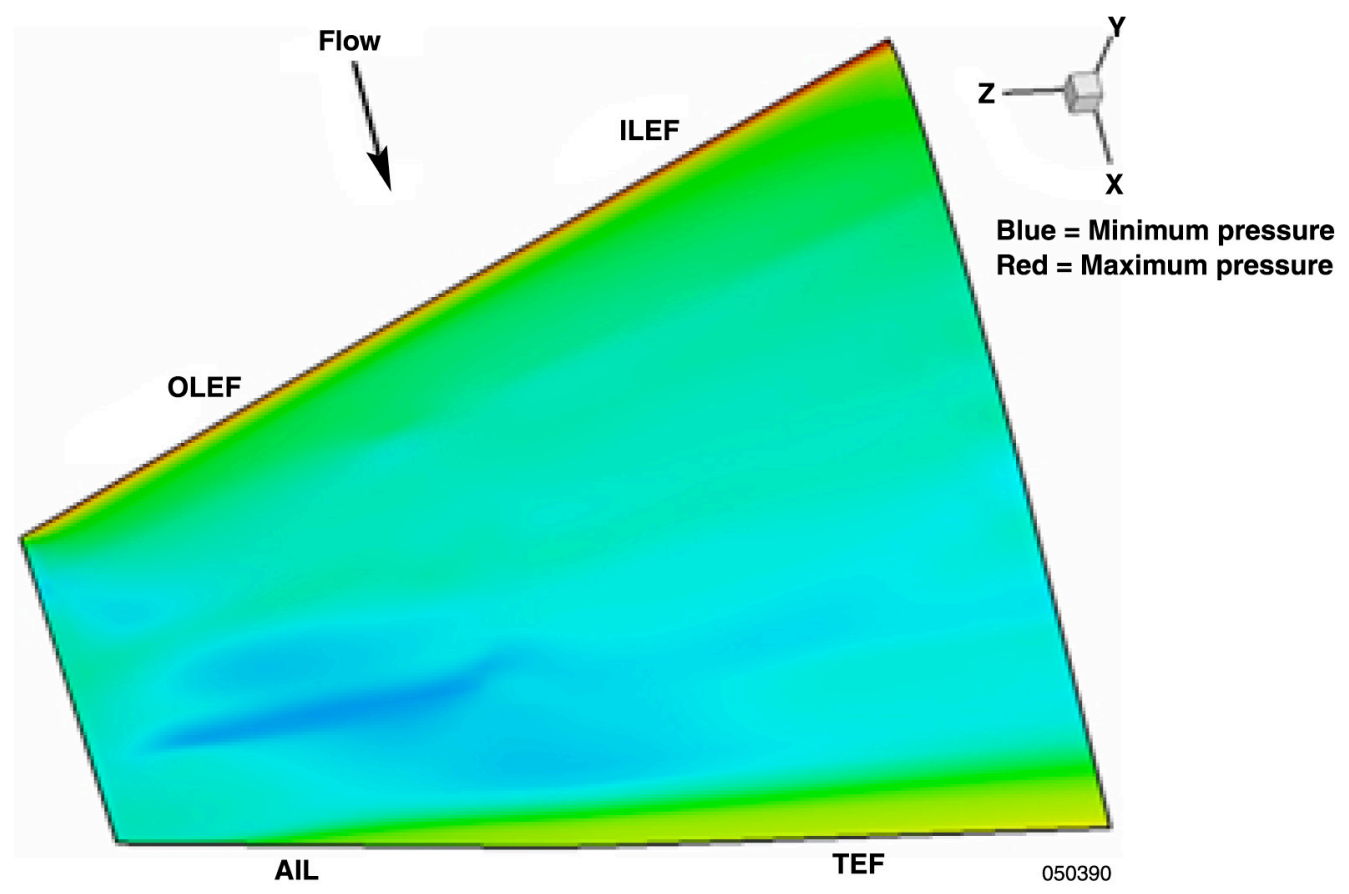

Figure 9. Undeflected wing upper surface pressure contour, Mach 0.97. 


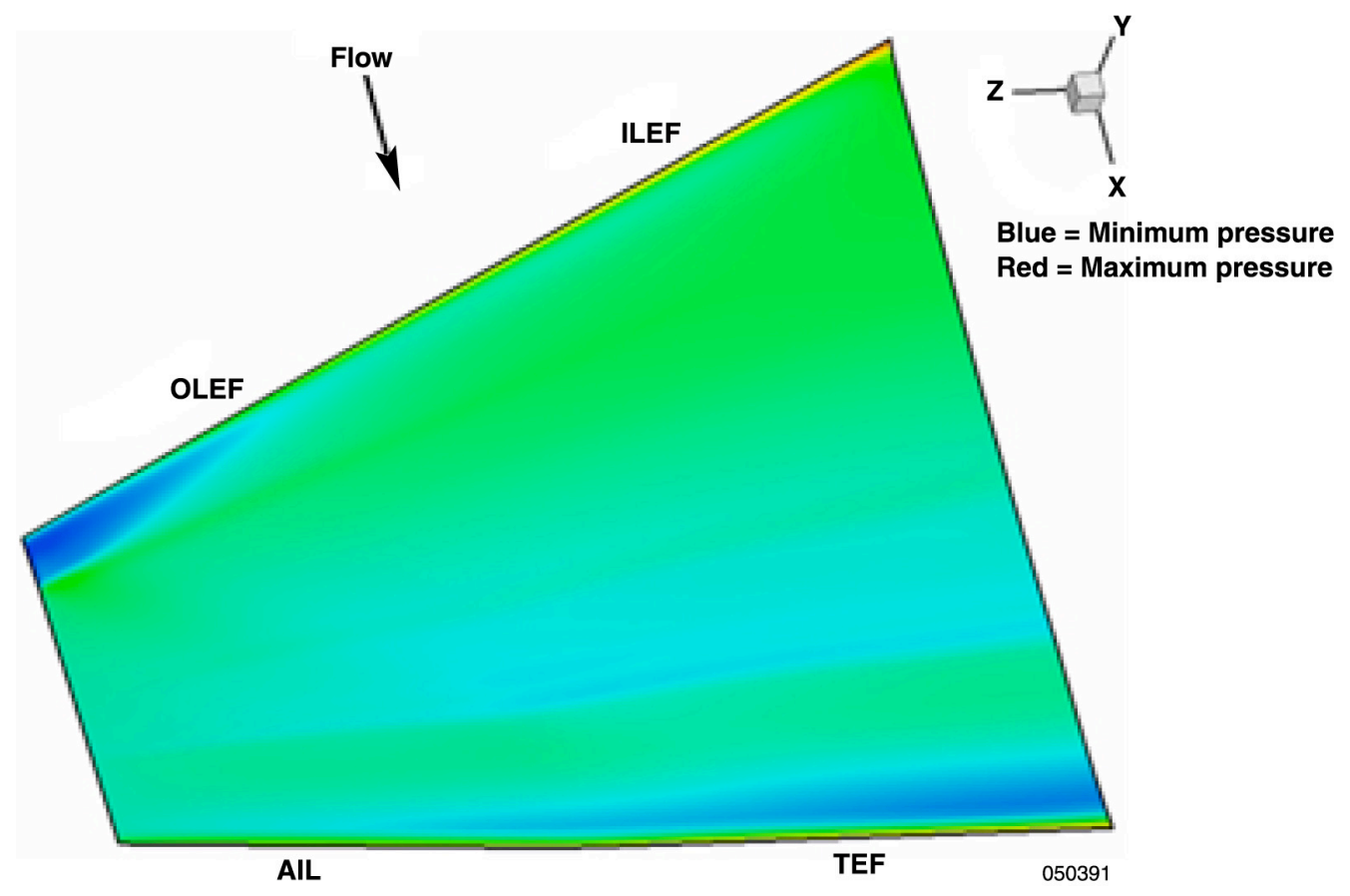

Figure 10. Undeflected wing lower surface pressure contour, Mach 0.97.

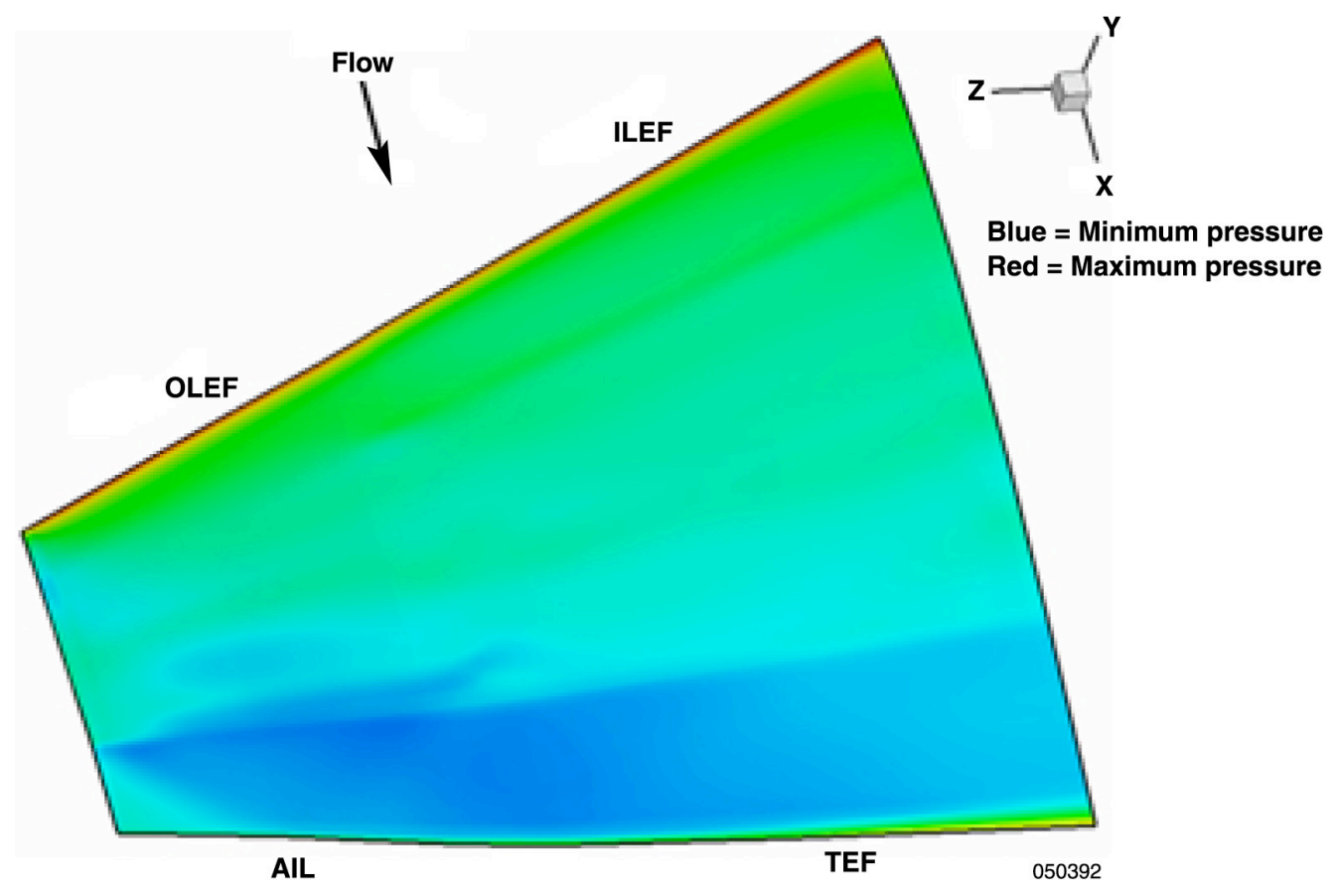

Figure 11. Flight deflection measurement system: deflected wing upper surface pressure contour, Mach 0.97. 


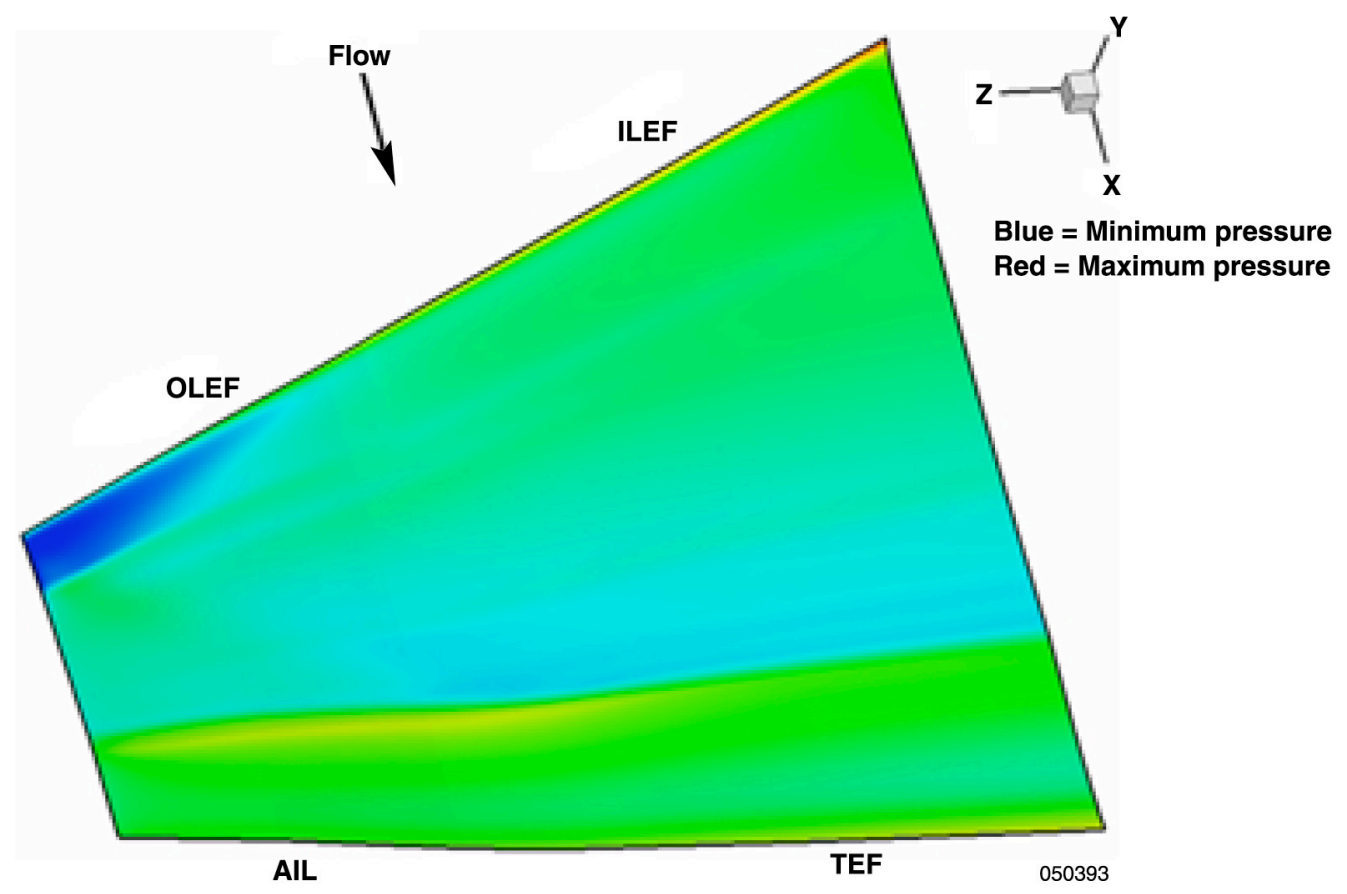

Figure 12. Flight deflection measurement system: deflected wing lower surface pressure contour, Mach 0.97.

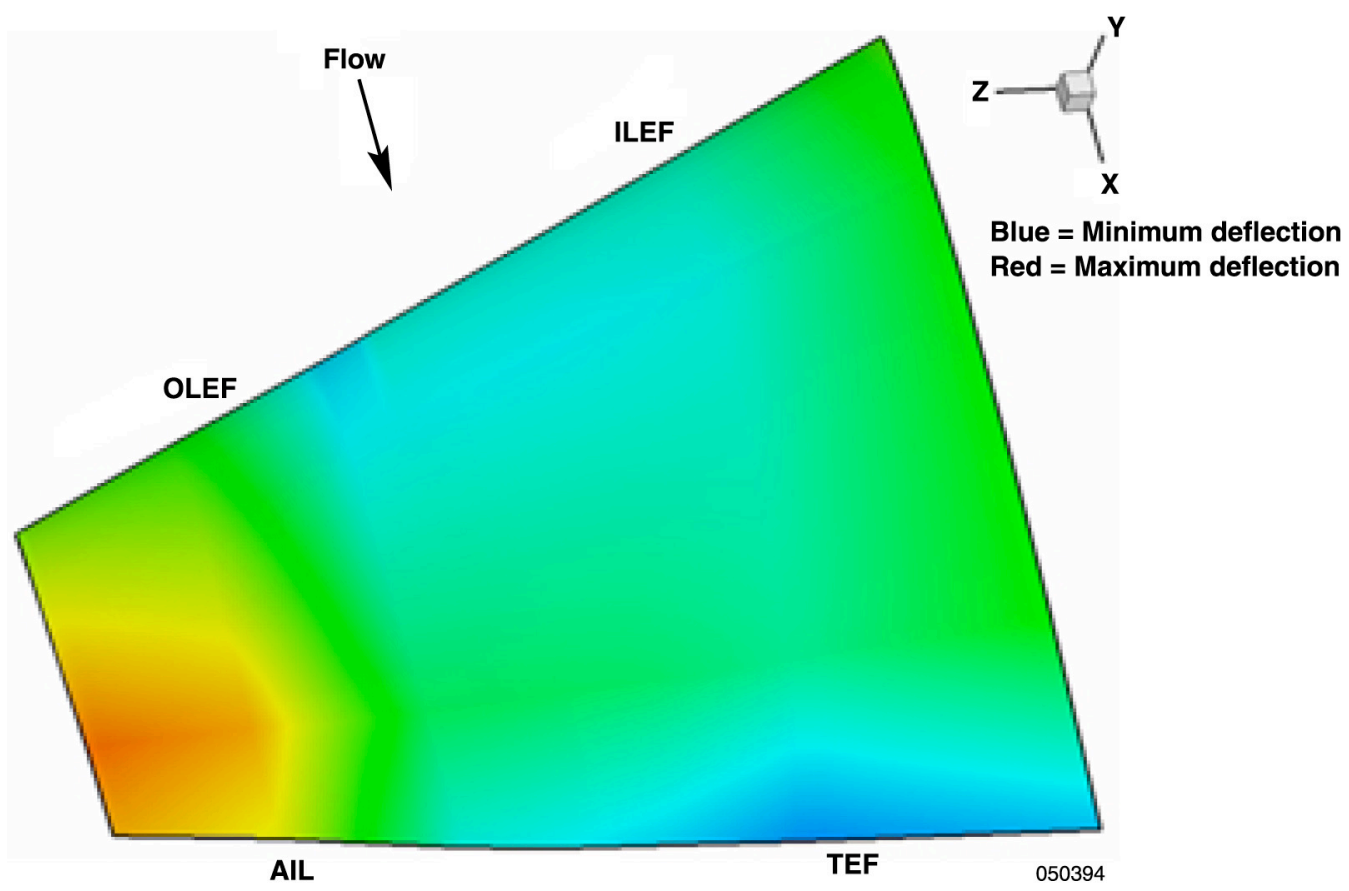

Figure 13. Flight deflection measurement system: measured deflection contour for the left upper wing surface, Mach 0.97 . 
A comparison of the flight research video and rigid CFD predicted surface pressure distributions shows general agreement and supports the interpretation that the shock translation directly caused the significant load change observed in the trailing-edge control surface hinge moments. This general agreement is qualitative, because the CFD predicted shock magnitudes and locations for each Mach number do not match those shown for the trailing-edge surfaces in figures 3 and 4 . Figures 14 and 15 show the resultant (lower minus upper) pressure distributions for the rigid CFD cases and FDMS-CFD cases, respectively. The contour scale is identical for both cases, with a symmetric, downward (blue) to upward (red) spectrum. These results show both the extreme pressure magnitudes and matching Mach numbers, Mach 0.95 (higher pressure) and 0.99 (lower pressure), for the left trailing-edge flap (LTEF), and Mach 0.96 for the left aileron (LAIL) for the transonic shock wave depicted in figures 3 and 4. Further analysis of the results and flight research data is expected to verify this observation.

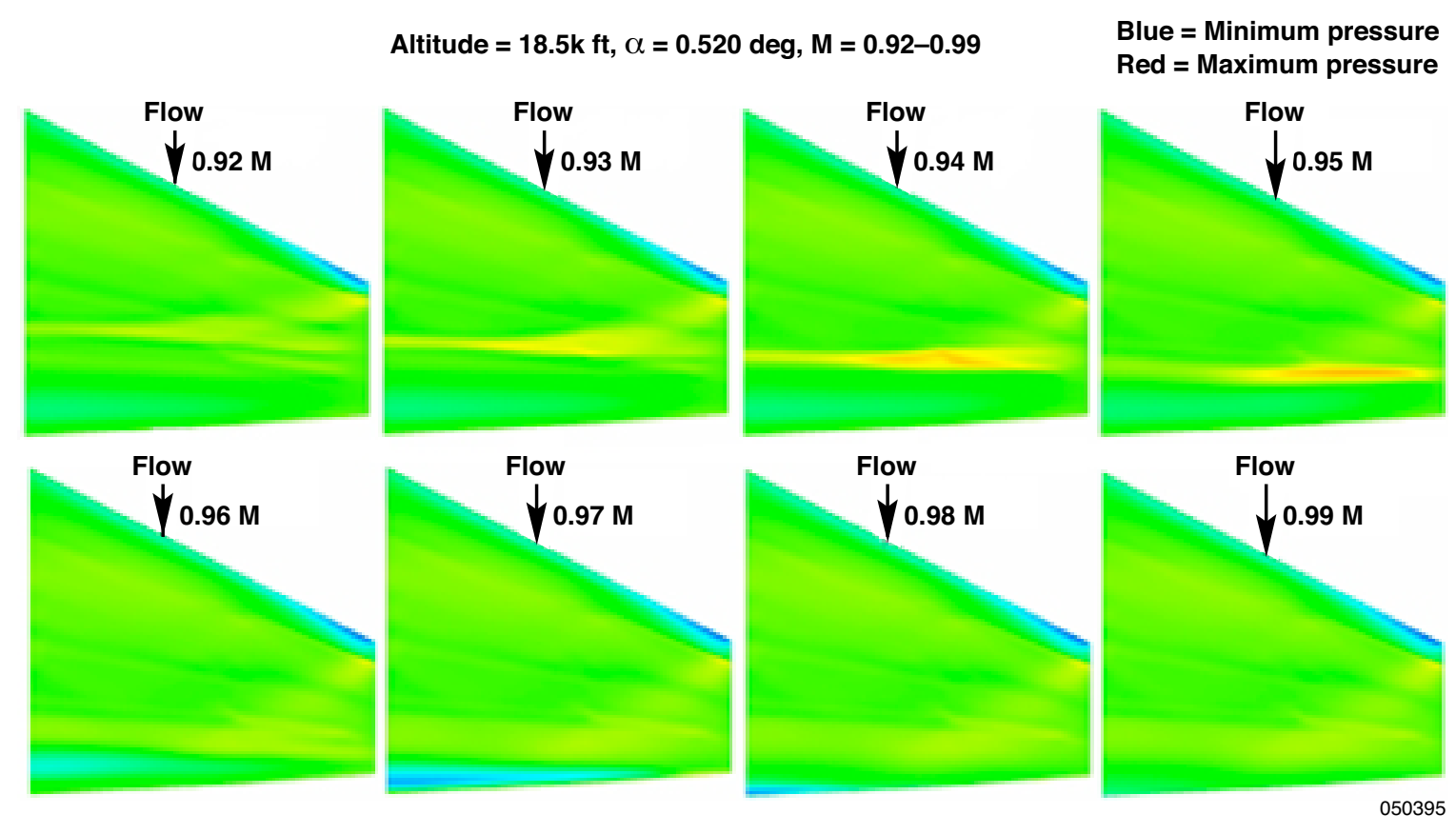

Figure 14. Rigid computational fluid dynamics resultant pressure distributions. 


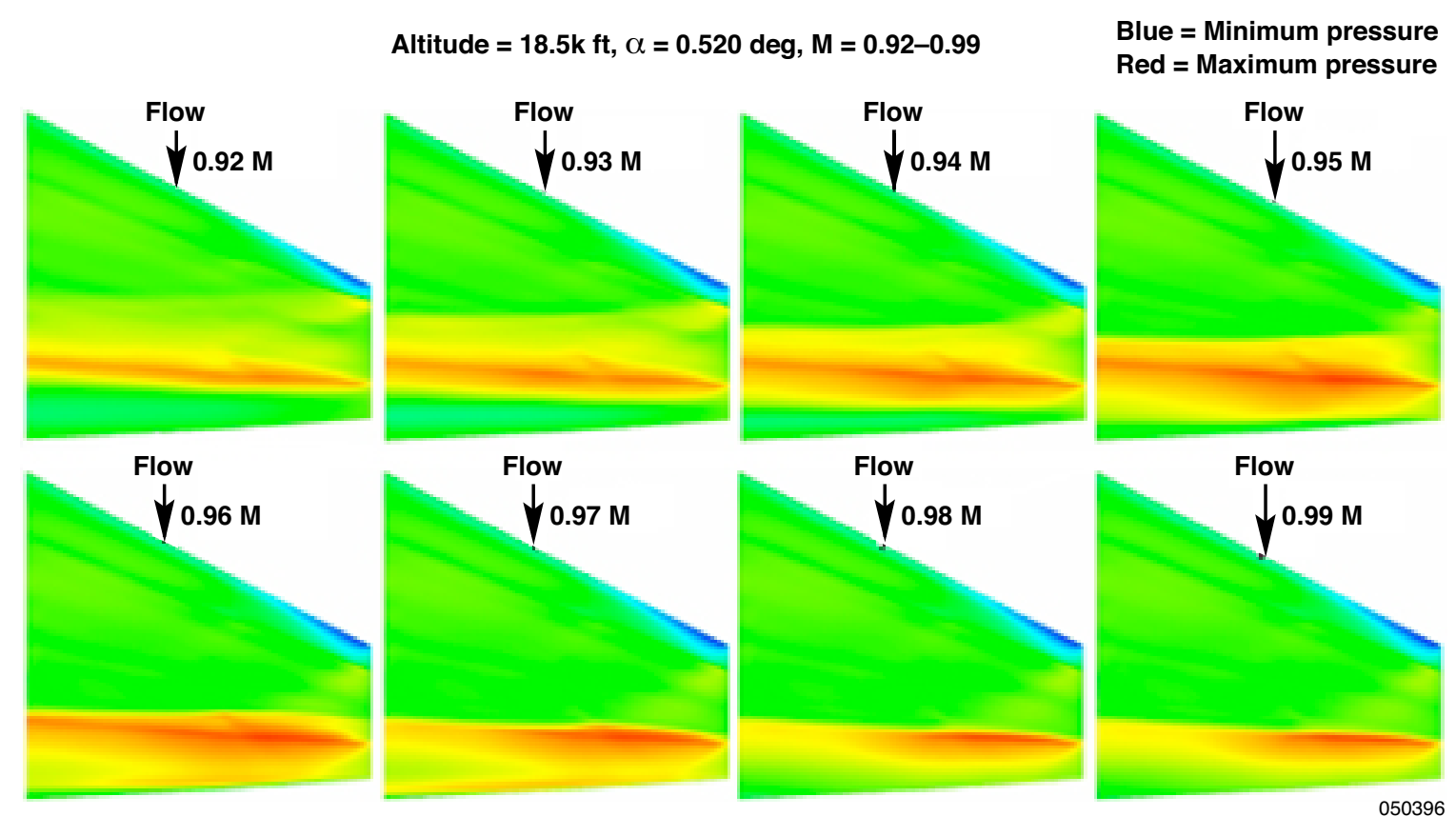

Figure 15. Flight deflection measurement system computational fluid dynamics resultant pressure distributions.

\section{Comparison of CFD Analysis to Flight-Measured Data}

For each Mach number, the surface pressure distributions shown in figures 9-12 were integrated over each control surface, in addition to the inboard and outboard wing boxes, to produce a set of forces $\left(F_{x}\right.$, $\left.F_{y}, F_{z}\right)$ and centroids $\left(X_{c}, Y_{c}, Z_{c}\right)$. The cross product of these forces and their respective moment arms rendered a hinge moment for each of the four control surfaces, and values for shear, bending, and torque at the wing fold and wing root. Eight of these ten loads (wing-root and wing-fold shears excluded), in addition to the total lift generated by the wing, then were compared to those measured during flight research.

Figure 16 shows the left wing trailing-edge flap deflections, which were measured at both the inboard and outboard edges of all wing control surfaces. Because the control surface transmissions are inboard mounted, their outboard deflections are more "free" to deflect under aerodynamic pressure loading. The corresponding extreme outboard deflections at Mach 0.95 and 0.99 for the LTEF- $o b$ and Mach 0.96 for the LAIL- $o b$ reinforce the FDMS-CFD resultant pressure distributions shown in figure 15. 


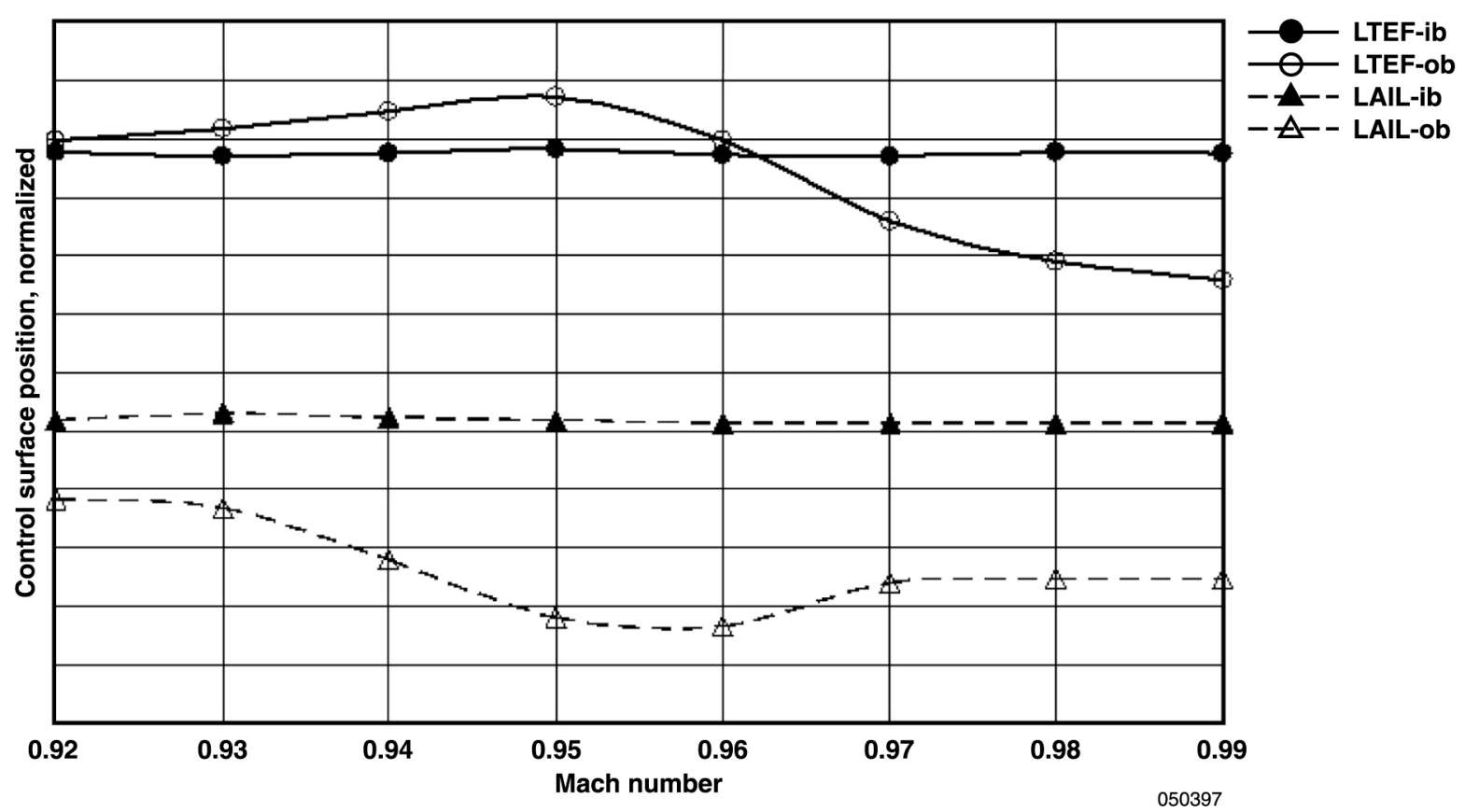

Figure 16. Left wing trailing-edge flap deflections.

Figure 17 shows the FDMS-CFD calculated centroids of the resultant aeroelastic forces on the wing and control surfaces. These results make physical sense, given that the centroid locations (1) move aft with increasing Mach number, and (2) are located within the wing and control surface boundaries.

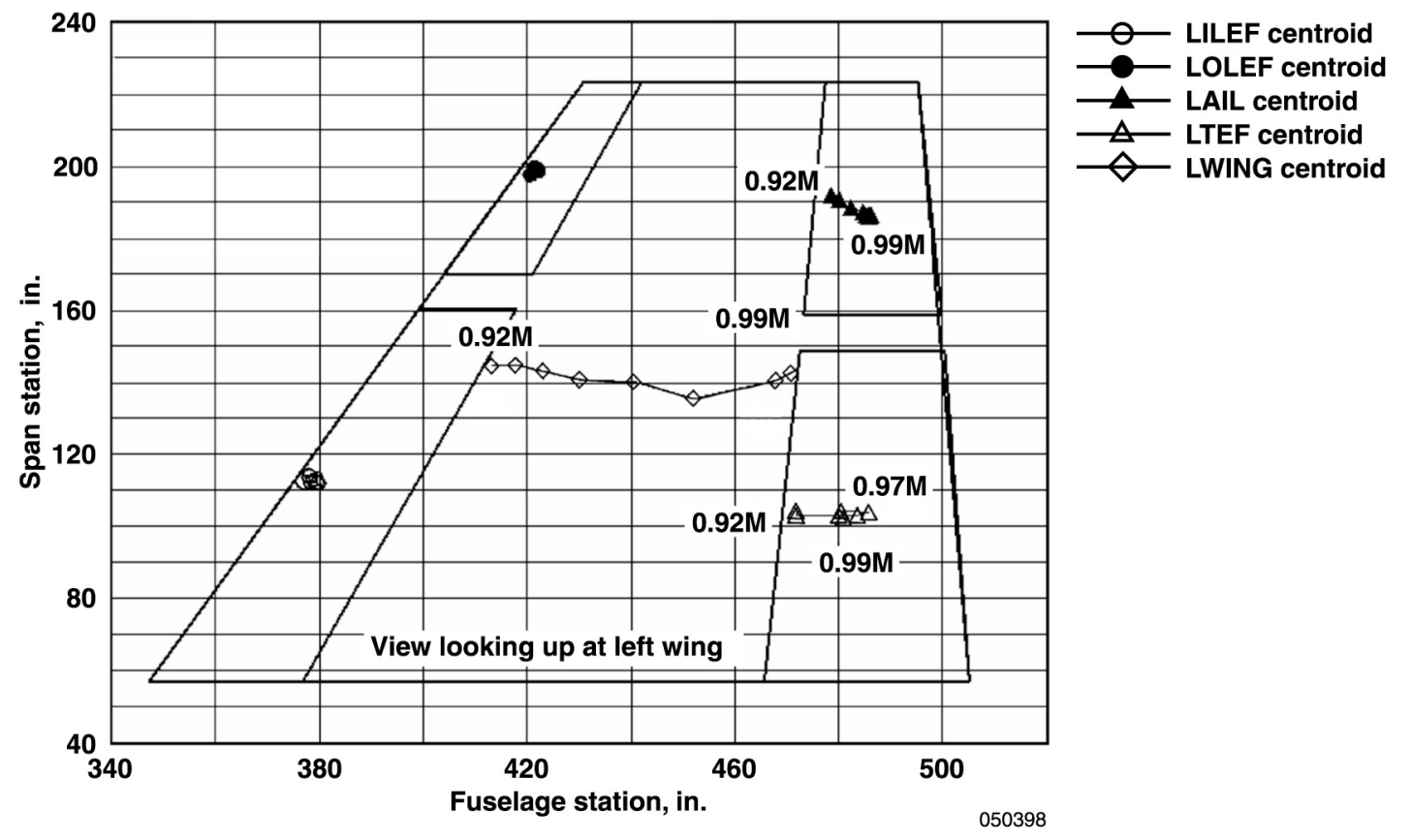

Figure 17. Left wing box and control surface load centroid locations. 
Figure 18 compares the measured left inboard leading-edge flap (LILEF) and left outboard leading-edge flap (LOLEF) hinge moments with those calculated using the FDMS-CFD. Excellent agreement was achieved with the LOLEF hinge moment, whereas the measured LILEF hinge moment magnitudes are less than those predicted but have the same general increasing trend. This discrepancy may be best explained by the fact that the CFD model does not include the (1) F/A-18 leading-edge extension, (2) fuselage for flow field boundary conditions, and (3) flow fence representation. The function of the flow fences on the F/A-18 aircraft is to move vortices away from the vertical tails to avoid buffet.

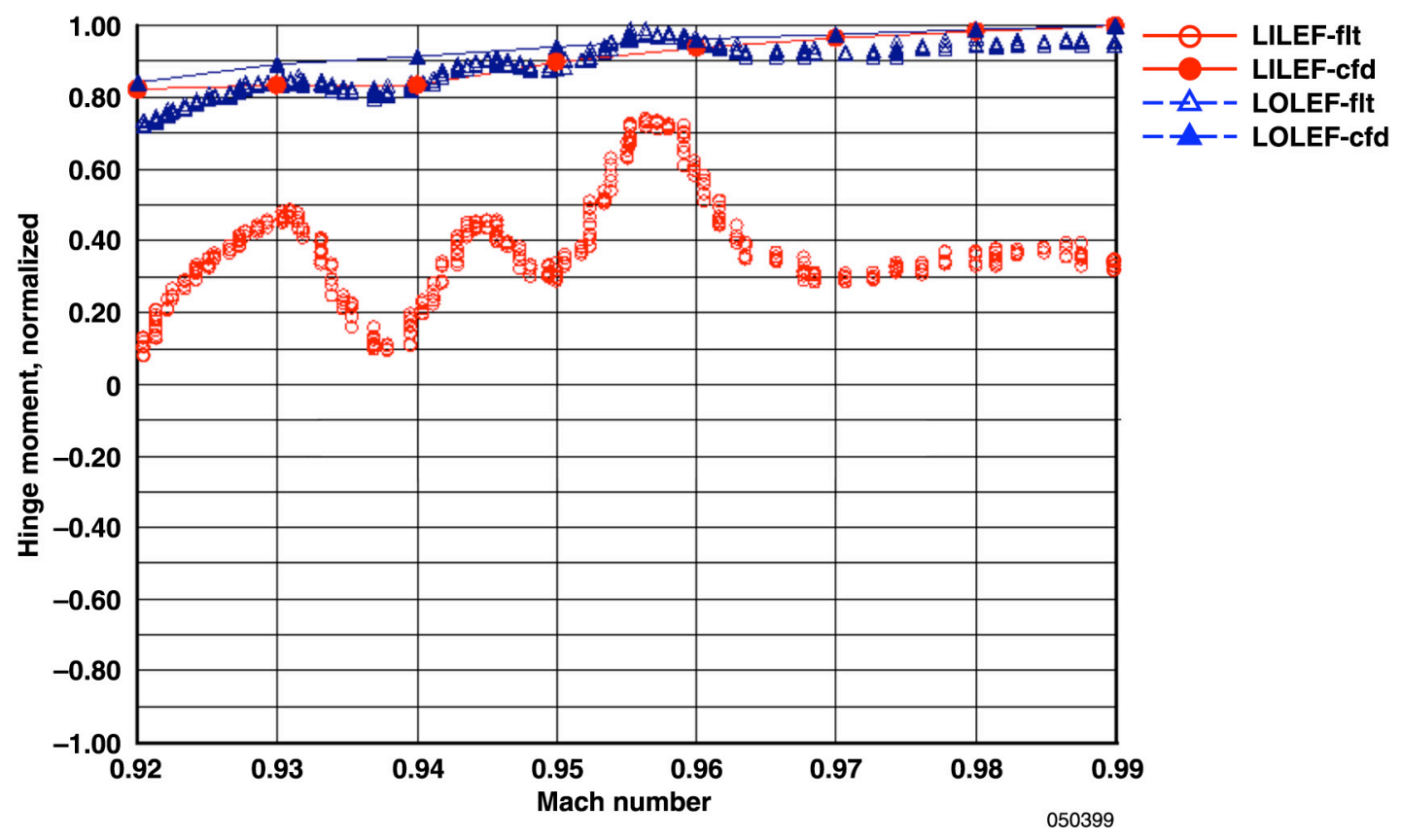

Figure 18. Left inboard and outboard leading-edge flap control surface hinge moments.

As shown in figure 19, even less agreement, both qualitative and quantitative, was achieved for the LTEF hinge moment. The three explanations for the LILEF discrepancy also apply to the LTEF discrepancy, and their effects are magnified when the position of the LTEF farther aft in the flow field is considered. Also highly important is the lack of a stabilator in the CFD modeling, because its interaction with the LTEF is known to be highly coupled. The aerodynamic upwash from the stabilator on the inboard portion of the wing resulting from their physical proximity is still evident at these transonic conditions. The effect of the stabilator on the total lift force generated by the wing also was very high, and this interaction was accounted for by coupling the FDMS-CFD with an assumed coefficient of lift for the stabilator. 


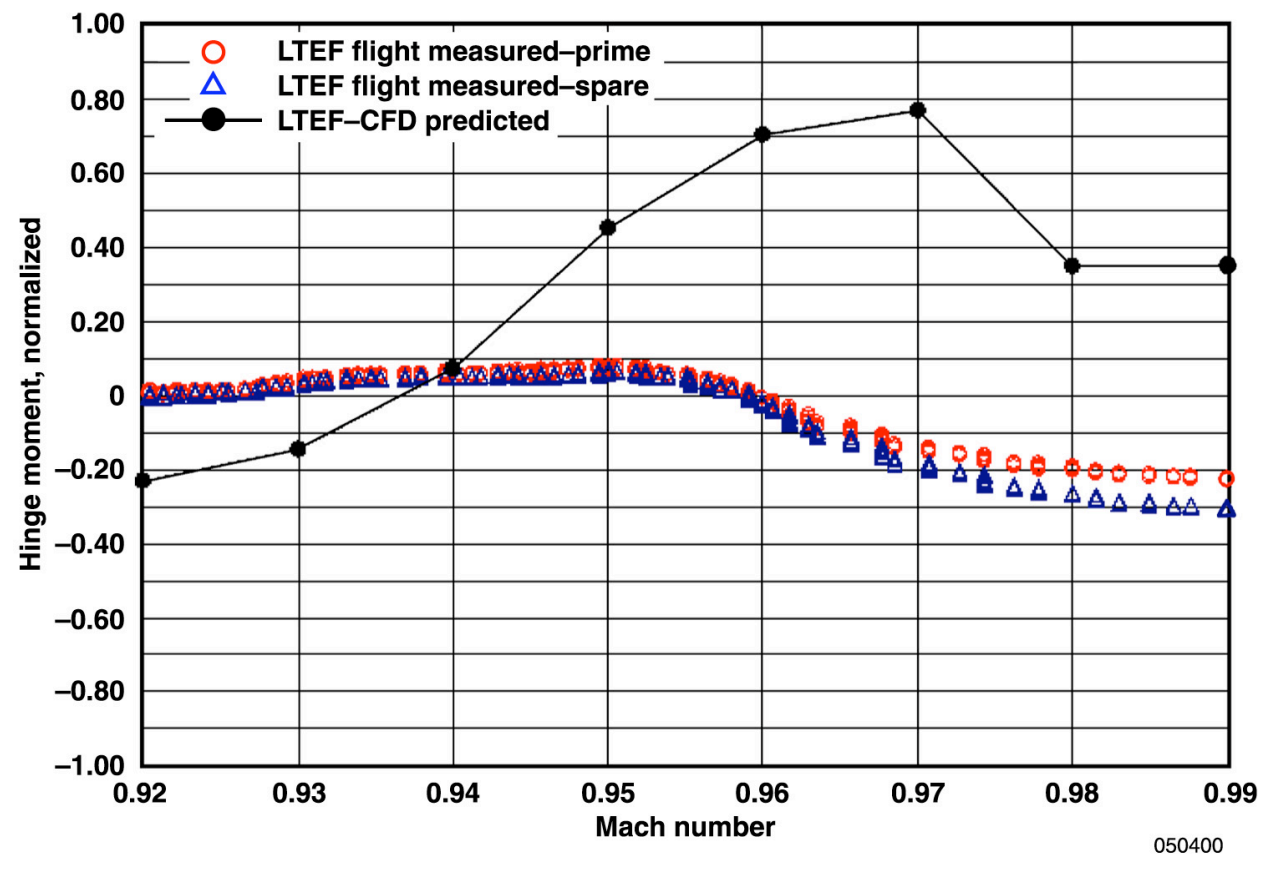

Figure 19. Left trailing-edge flap control surface hinge moment.

Figure 20 compares the measured and predicted LAIL hinge moments. Similar to the LOLEF, the load history of this outboard surface was very well predicted (both qualitatively and quantitatively) by FDMS-CFD. Figures 21 and 22 compare the measured and predicted bending moment and torque at the wing root and wing fold, respectively. Generally good qualitative and quantitative agreement was achieved for the wing-root bending moments; the wing-fold bending moments were smaller in magnitude than the wing-root bending moments. 


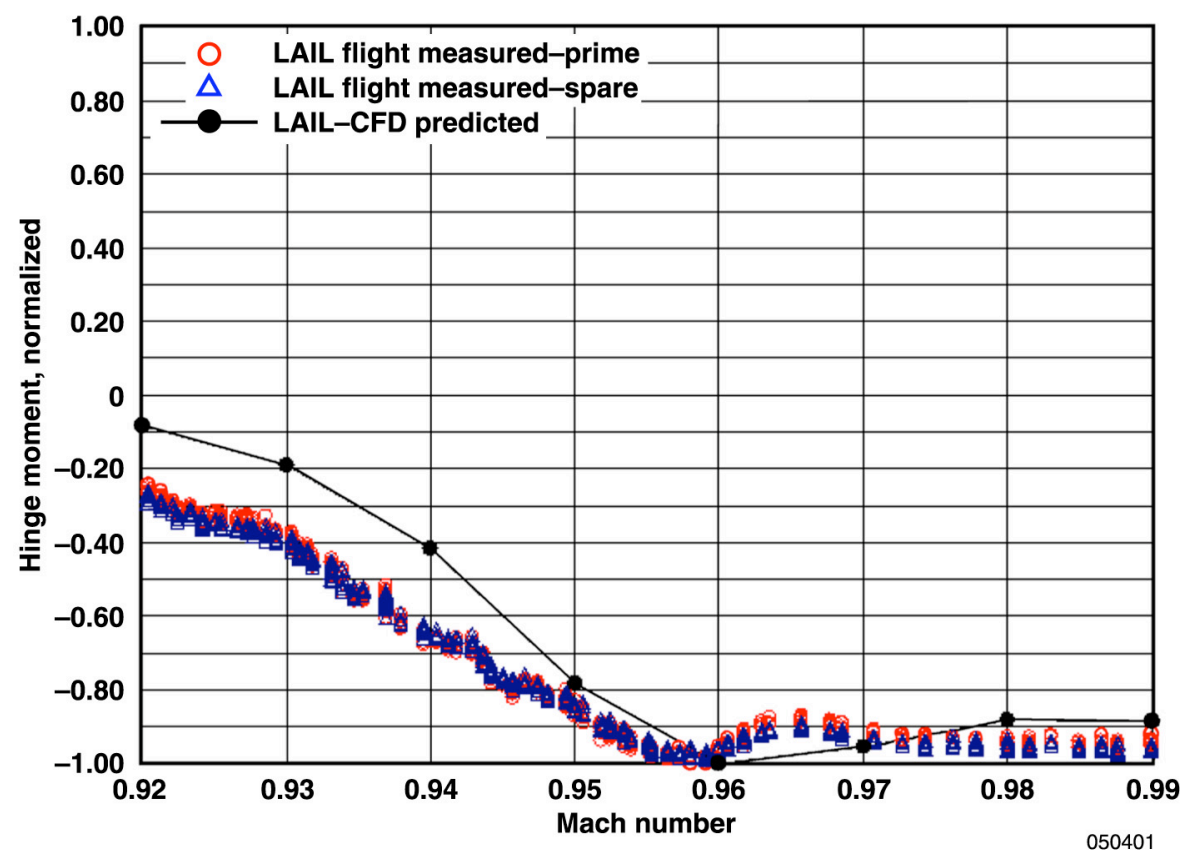

Figure 20. Left aileron control surface hinge moment.

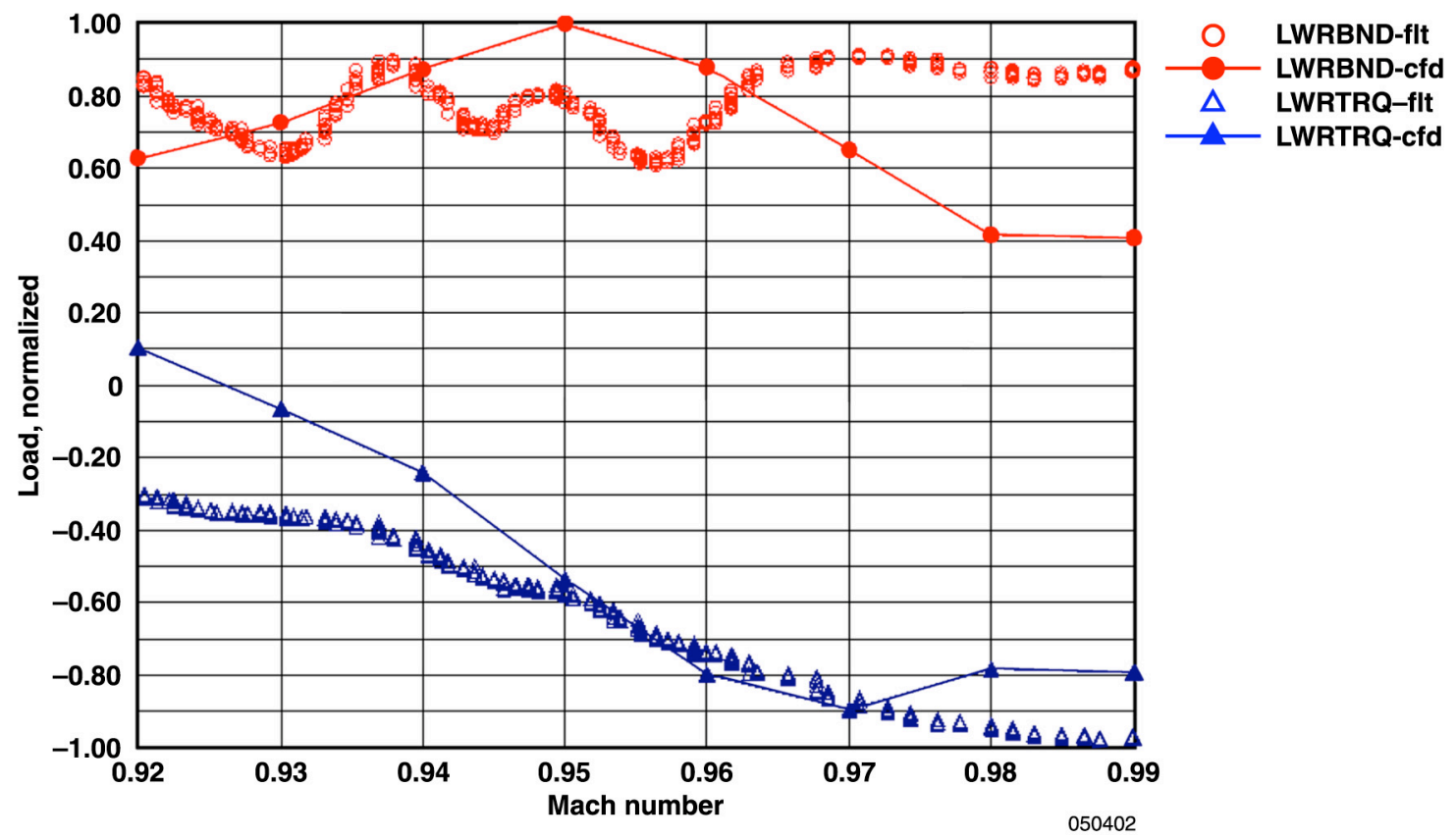

Figure 21. Left wing-root bending moment and torque comparison. 


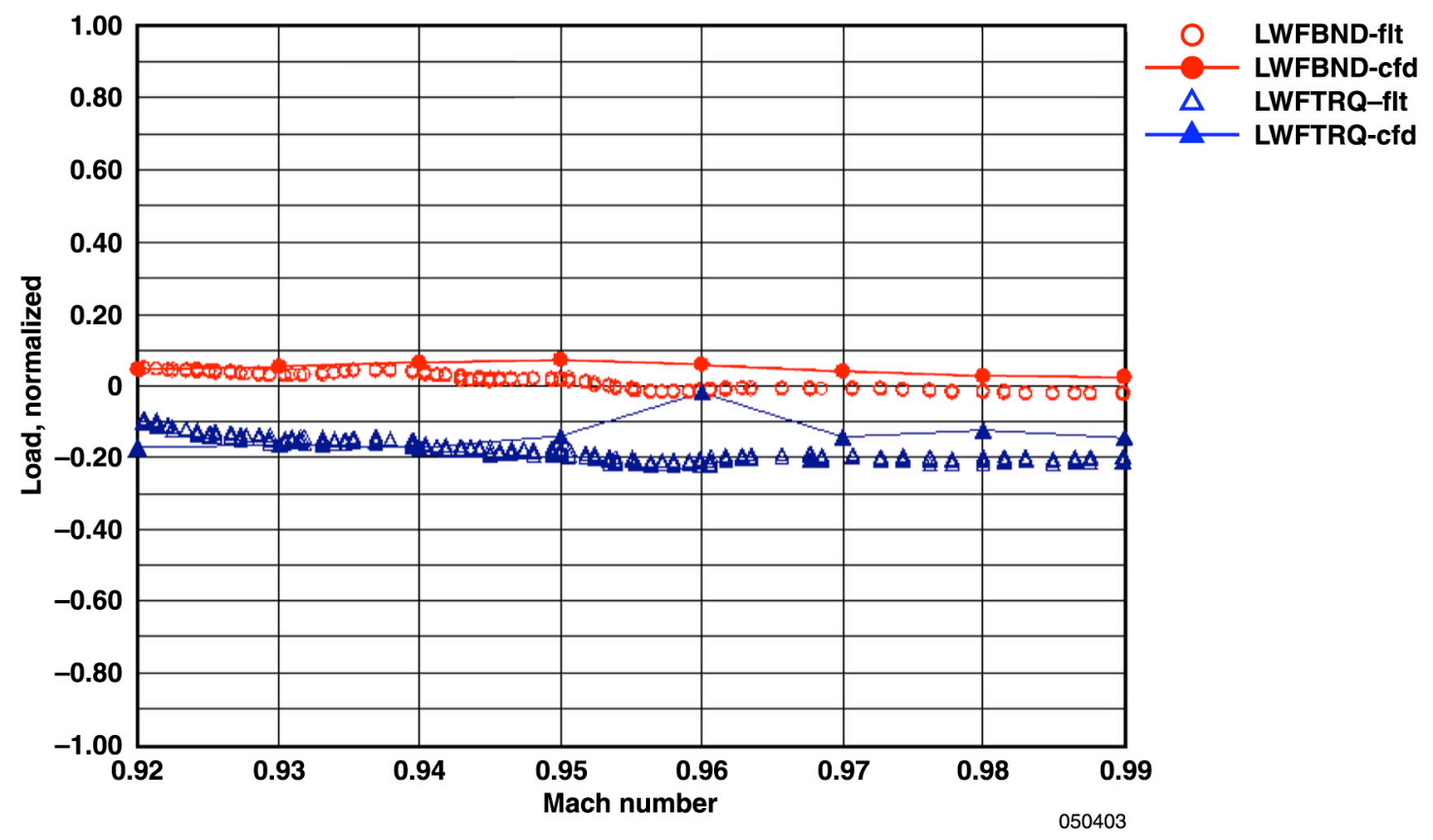

Figure 22. Left wing-fold bending moment and torque comparison.

\section{Importance of Stabilator Consideration When Modeling}

Because this flight event was trimmed and nominally level, the FDMS-CFD lift force generated by the wing would be expected to remain constant with respect to Mach number. This relationship, however, is not obvious. Figure 23 shows the left stabilator position, on which the air vehicle trim condition is dependent, as a function of Mach number. The stabilator position varied throughout the maneuver. Therefore, for understandable reasons, the FDMS-CFD generated history of the lift produced by the wing also varied throughout the level acceleration. Figure 24 shows the total lift of the wing and the lift force generated by the wing, in addition to that generated by the left stabilator when a constant stabilator lift coefficient was assumed. The slight increase in overall lift force from Mach numbers 0.96 to 0.99 also is reflected in an increase in altitude for those Mach numbers, as shown in figure 25. Therefore, although this flight event was nominally level, the contribution to the total aircraft lift produced by the stabilator was consistent with the slight variation in altitude during the maneuver time interval. The stabilator position variation also has implications in understanding the trailing-edge flap predictions, as previously discussed. 


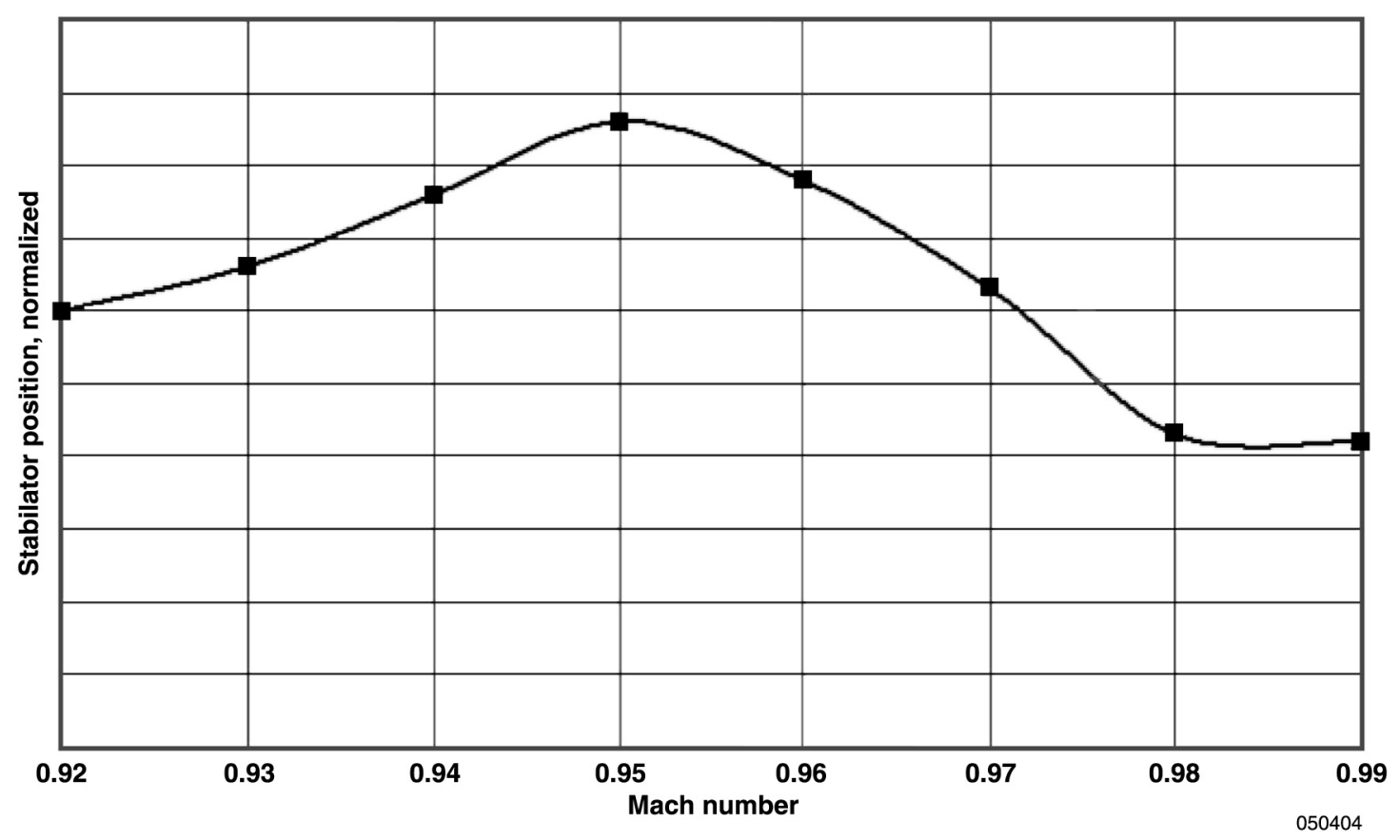

Figure 23. Left stabilator position as a function of Mach number.

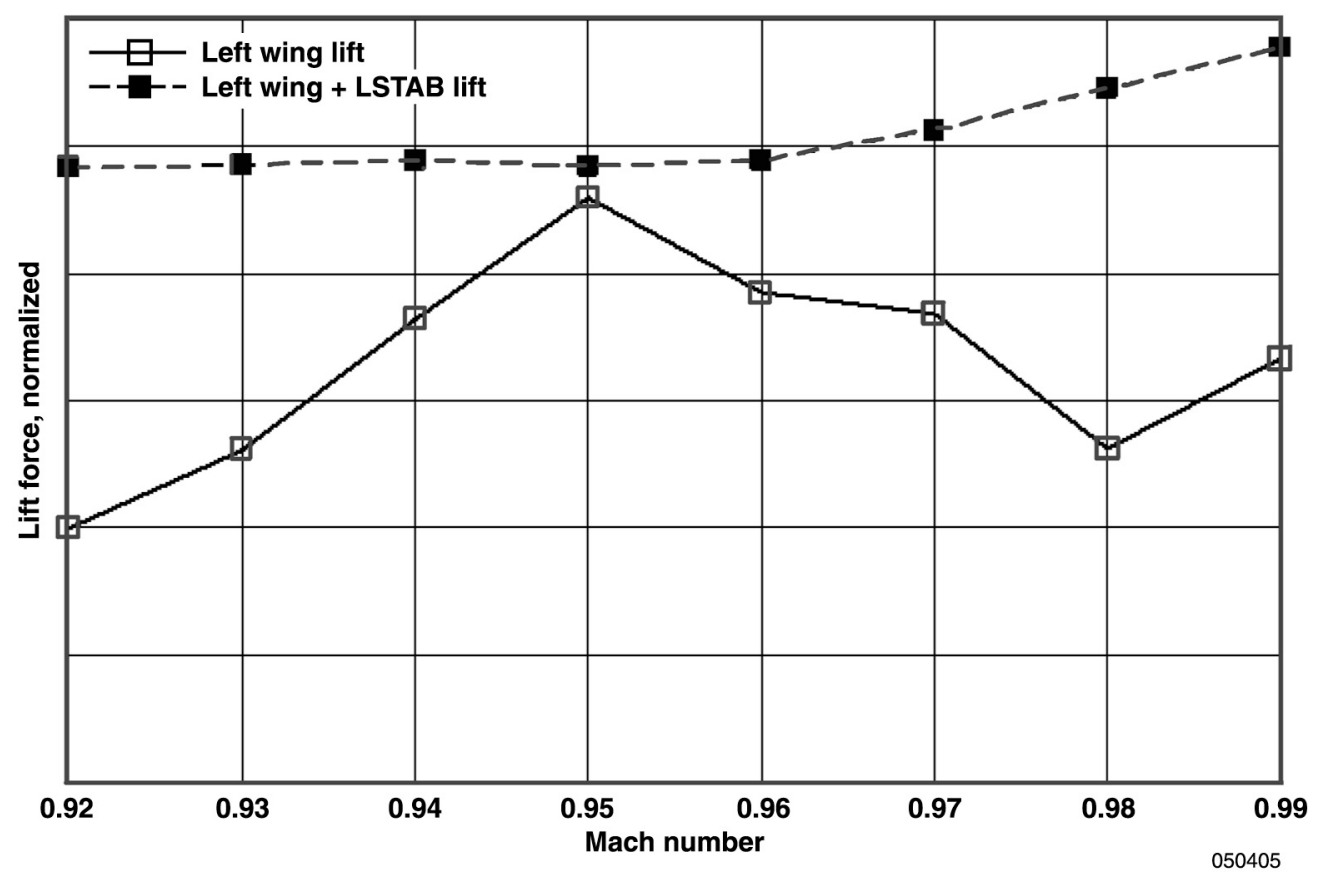

Figure 24. Flight deflection measurement system computational fluid dynamics lift force comparison. 


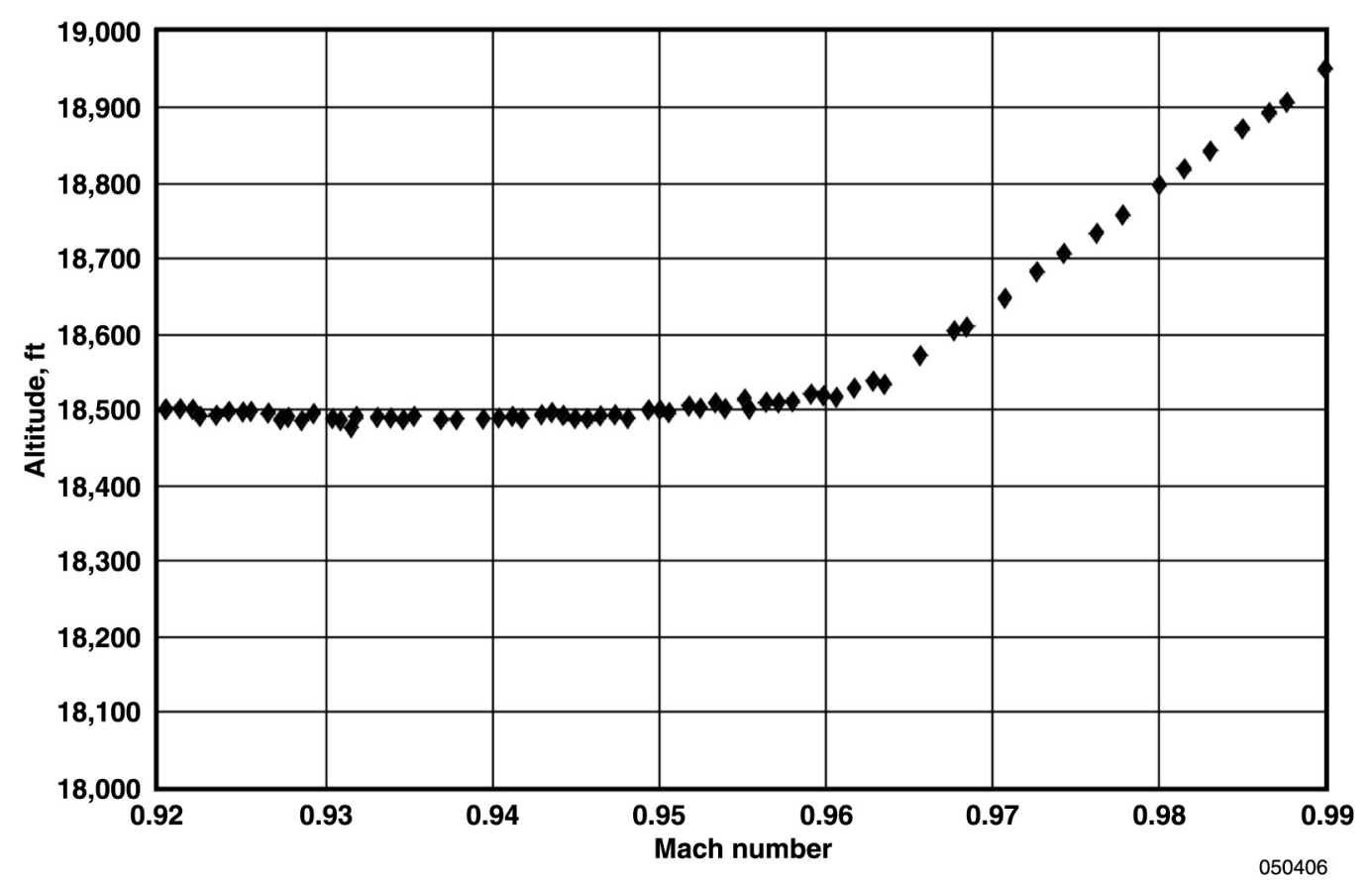

Figure 25. Altitude as a function of Mach number.

\section{CONCLUDING COMMENTS}

In level transonic flight, the shock location dominated the wing trailing-edge control surface hinge moments. The predictive method of the computational fluid dynamics (CFD) based on the elastic shape provided by the flight deflection measurement system (FDMS) produced very similar results and substantially correlated with the measured loads data. Specifically, the FDMS-CFD method qualitatively and quantitatively represented the flight loads for the outboard control surfaces, and to a slightly lesser extent for the wing-root moments. For inboard leading-edge surfaces and wing-fold moments on this vehicle, however, the correlation was more qualitative. Moreover, the inboard trailing-edge control surface predictions were the least accurate of those studied, lacking both qualitative and quantitative agreement. These shortcomings in predictive performance have understandable physical explanations that can be compensated for, however, if the computational expense of a full vehicle model is deemed acceptable. In-flight video, which first captured the attention of the flight research engineers and was confirmed through the measured data, sometimes has unexpected value.

\section{Dryden Flight Research Center}

National Aeronautics and Space Administration

Edwards, California, July 15, 2005 


\section{REFERENCES}

1. Miller, Gerald D., “Active Flexible Wing (AFW) Technology,” Air Force Wright Aeronautical Laboratories, TR-87-3096, Feb. 1988.

2. Miller, Gerald D., "An Active Flexible Wing Multi-Disciplinary Design Optimization Method," AIAA-94-4412-CP, 1994.

3. Yurkovich, Rudy, "Optimum Wing Shape for an Active Flexible Wing," AIAA-95-1220-CP, 1995.

4. Pendleton, Ed, Kenneth E. Griffin, Michael W. Kehoe, and Boyd Perry, "A Flight Research Program for Active Aeroelastic Wing Technology," AIAA-96-1574-CP, 1996.

5. Pendleton, Edmund W., Denis Bessette, Peter B. Field, Gerald D. Miller, and Kenneth E. Griffin, "Active Aeroelastic Wing Flight Research Program: Technical Program and Model Analytical Development," Journal of Aircraft, Vol. 37, No. 4, July-Aug. 2000.

6. Voracek, David, Ed Pendleton, Eric Reichenbach, Dr. Kenneth Griffin, and Leslie Welch, The Active Aeroelastic Wing Phase I Flight Research Through January 2003, NASA TM-2003-210741, 2003.

7. Fisher, David F., Edward A. Haering, Jr., Gregory K. Noffz, and Juan I. Aguilar, Determination of Sun Angles for Observations of Shock Waves on a Transport Aircraft, NASA TM-1998-206551, 1998.

8. Lokos, William A., Candida D. Olney, Tony Chen, Natalie D. Crawford, Rick Stauf, and Eric Y. Reichenbach, Strain Gage Loads Calibration Testing of the Active Aeroelastic Wing F/A-18 Aircraft, NASA TM-2002-210726, 2002.

9. DeAngelis, V. Michael, and Robert Fodale, "Electro-Optical Flight Deflection Measurement System," SFTE 18th Annual Symposium Proceedings, SFTE Technical Paper 22, Amsterdam, Netherlands, Sept. 1987.

10. Lokos, William A., Predicted and Measured In-Flight Wing Deformations of a Forward-Swept-Wing Aircraft, NASA TM-4245, 1990.

11. Lokos, William A., Catherine M. Bahm, and Robert A. Heinle, Determination of Stores Pointing Error Due to Wing Flexibility Under Flight Load, NASA TM-4646, 1995.

12. Lizotte, Andrew M., and William A. Lokos, Deflection-Based Structural Loads Estimation From the Active Aeroelastic Wing F/A-18 Aircraft, NASA TM-2005-212871, 2005.

13. Burner, Alpheus W., William A. Lokos, and Danny A. Barrows, "Aeroelastic Deformation: Adaptation of Wind Tunnel Measurement Concepts to Full-Scale Vehicle Flight Testing," NATO RTO-MP-AVT-124, Paper No. 9, Research and Technology Organization Specialists' Meeting on Recent Developments in Non-Intrusive Measurement Technology for Military Application on Modeland Full-Scale Vehicles, Budapest, Hungary, April 25-28, 2005. 
14. Schuster, David M., Joseph Vadyak, and Essam Atta, "Static Aeroelastic Analysis of Fighter Aircraft Using a Three-Dimensional Navier-Stokes Algorithm," Journal of Aircraft, Vol. 27, No. 9, Sept. 1990, pp. 820-825.

15. Lizotte, Andrew M., and Michael J. Allen, Twist Model Development and Results From the Active Aeroelastic Wing F/A-18 Aircraft, NASA TM-2005-212861, 2005. 
The public reporting burden for this collection of information is estimated to average 1 hour per response, including the time for reviewing instructions, searching existing data sources, gathering and maintaining the data needed, and completing and reviewing the collection of information. Send comments regarding this burden estimate of any other aspect of this collection of information, including suggestions for reducing this burden, to Department of Defense, Washington Headquarters Services,

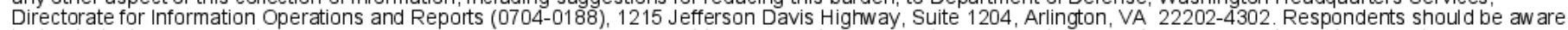
that notwithstanding any other provision of law, no person shall be subject to any penalty for failing to comply with a collection of information if it does not display a currently valid OMB control number.

PLEASE DO NOT RETURN YOUR FORMTO THE ABOVEADDRESS
1. REPORT DATE (DD-MM-YYYY)
2. REPORT TYPE
05-12-2005
Technical Memorandum
3. DATES COVERED (From - To)

4. TITLE AND SUBTITLE

Shock Location Dominated Transonic Flight Loads on the Active Aeroelastic Wing

5a. CONTRACT NUMBER

5b. GRANT NUMBER

5c. PROGRAM ELEMENT NUMBER

6. AUTHOR(S)

William A. Lokos, Andrew Lizotte, Ned J. Lindsley, and Rick Stauf

5d. PROJECT NUMBER

5e. TASK NUMBER

5f. WORK UNIT NUMBER

7235600 SE R 00000

\section{PERFORMING ORGANIZATION NAME(S) AND ADDRESS(ES)}

NASA Dryden Flight Research Center

8. PERFORMING ORGANIZATION

P.O. Box 273

Edwards, CA 93523-0273

$\mathrm{H}-2620$

9. SPONSORINGIMONITORING AGENCY NAME(S) AND ADDRESS(ES)

National Aeronautics and Space Administration

Washington, DC 20546-0001

REPORT NUMBER

10. SPONSORINGIMONITOR'S ACRONYM(S)

NASA

11. SPONSORINGIMONITORING REPORT NUMBER

NASA/TM-2005-213667

12. DISTRIBUTIONIAVAILABILITY STATEMENT

Unclassified-Unlimited

Subject Category 05

Availability: NASA CASI (301) 621-0390 Distribution: Standard

\section{SUPPLEMENTARY NOTES}

Also presented at the AIAA Atmospheric Flight Mechanics Conference and Exhibit, San Francisco, CA, August 15-18, 2005.

\section{ABSTRACT}

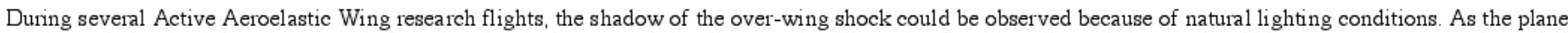

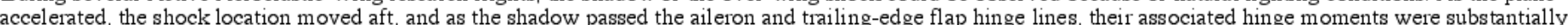

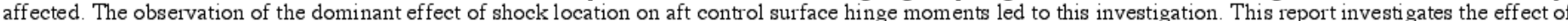

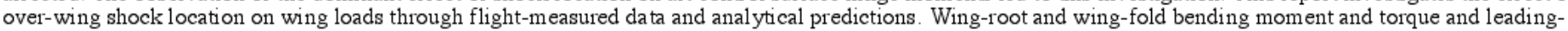
and trailing-edge hinge moments have been measured in flight using calibrated strain gages. These same loads have been predicted using a computational fluid

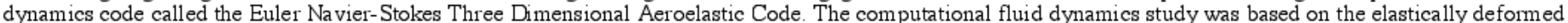

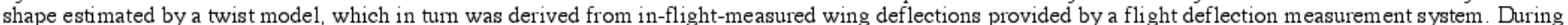

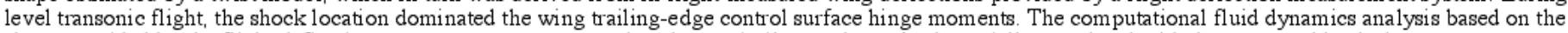
shape provided by the flight deflection measurement system produced very similar results and substantially correlated with the measured loads data.

\section{SUBJECT TERMS}

Active aeroelastic wing, Control surface hinge moments, Flight deflection measurement system, Predicted and measured loads, Transonic shock location

16. SECURITY CLASSIFICATION OF:

\begin{tabular}{|l|l|l|}
\hline a. REPORT & b. ABSTRACT & c. THIS PAGE
\end{tabular}

$\mathrm{U}$

$\mathrm{U}$
17. LIMITATION OF ABSTRACT

U
UU 18. NUMBER PAGES

27 19a. NAME OF RESPONSIBLE PERSON STI Help Desk (email: help@sti.nasa.gov) 19b. TELEPHONE NUMBER (Include area code)

(301) 621-0390 